Priscila Raulickis de Mello

\title{
Efeito do Treinamento da Musculatura Inspiratória na Atividade Simpática, Hemodinâmica e Qualidade de Vida de Pacientes com Miocardiopatia Hipertensiva.
}

Tese apresentada à Faculdade de Medicina da Universidade de São Paulo para obtenção do título de Doutor em Ciências.

Área de Concentração: Cardiologia

Orientadora: Dra. Fernanda Marciano Consolim Colombo

São Paulo 
Dados Internacionais de Catalogação na Publicação (CIP)

Preparada pela Biblioteca da

Faculdade de Medicina da Universidade de São Paulo

Creprodução autorizada pelo autor

Mello, Priscila Raulickis de

Efeito do treinamento da musculatura inspiratória na atividade simpática,

hemodinâmica e qualidade de vida de pacientes com miocardiopatia hipertensiva /

Priscila Raulickis de Mello. -- São Paulo, 2009.

Tese(doutorado)--Faculdade de Medicina da Universidade de São Paulo.

Departamento de Cardio-Pneumologia.

Área de concentração: Cardiologia.

Orientadora: Fernanda Marciano Consolim Colombo.

Descritores: 1.Músculos respiratórios 2.Insuficiência cardíaca 3.Sistema nervoso autônomo 4.Qualidade de vida

USP/FM/SBD-305/09 


\section{SUMÁRIO}

Lista de abreviaturas e siglas

Lista de figuras

Lista de tabelas

Resumo

Abstract

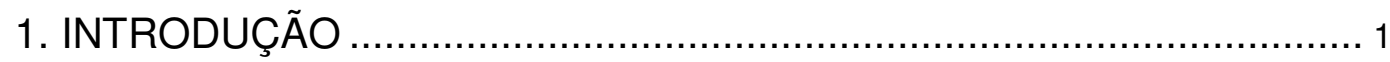

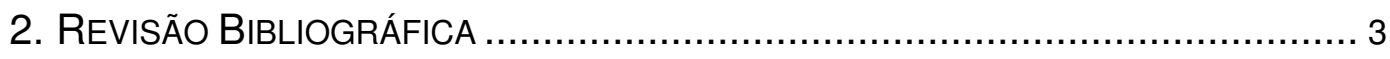

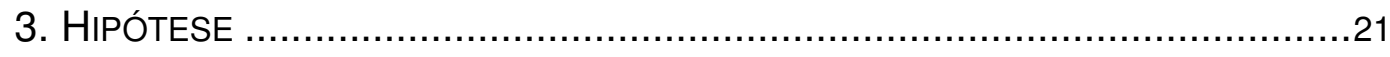

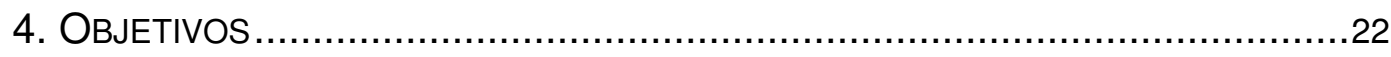

5. Casuística e MÉtodos

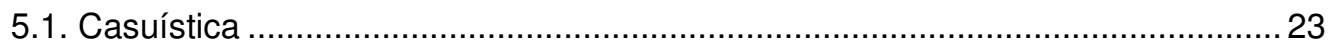

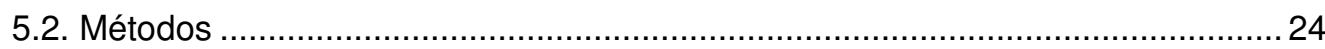

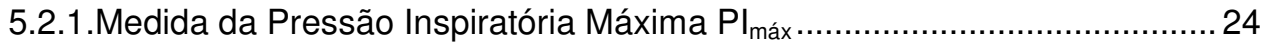

5.2.2 Registro das Variáveis Hemodinãmicas pelo Finometer ............................26

5.2.3 Avaliação da Capacidade Cardiorrespiratória (ergoespirometria) .............27

5.2.4 Avaliação da Atividade Nervosa Simpática Periférica (microneurografia) . 30

5.2.5. Análise da Variabilidade da FC e PA ...................................................... 31

5.2.6. Pletismografia por Oclusão Venosa ....................................................... 34

5.2.7. Questionário de Qualidade de Vida em pacientes com IC (Minessota) .... 35

5.2.8. Treinamento da Musculatura Inspiratória..............................................36

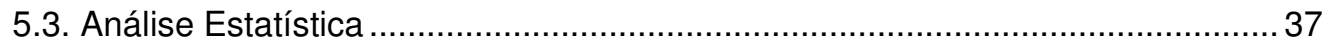

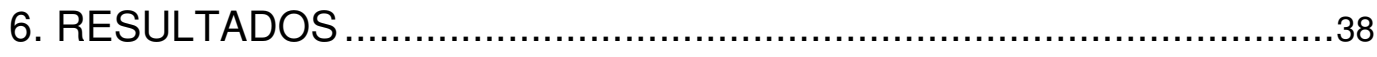

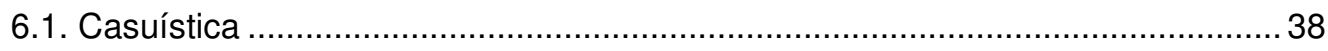

6.2. Efeito do TMI na força e resistência dos músculos inspiratórios ....................... 40

6.3. Efeito do TMI sobre as variáveis hemodinâmicas ........................................... 42 
6.4 Efeito do TMI na capacidade funcional cardiorrespiratória .................................43

6.5. Efeito do TMI na variabilidade da FC e PA e ANSP .......................................... 46

6.6. Efeito do TMI sobre o fluxo para o antebraço (FSA ) ......................................... 49

6.7. Efeito do TMI sobre a qualidade de vida dos pacientes com IC .........................51

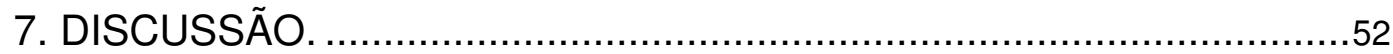

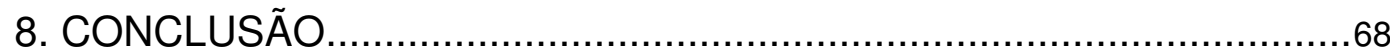

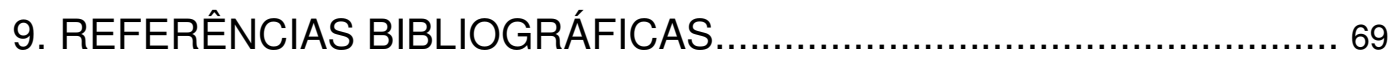

10. ANEXOS 


\section{RESUMO}

Mello PR. Efeito do Treinamento da Musculatura Inspiratória na Hemodinâmica, Atividade Simpática e Qualidade de Vida de Pacientes com Miocardiopatia Hipertensiva. São Paulo: Faculdade de Medicina, Universidade de São Paulo; 2009.

Introdução: Pacientes com Insuficiência Cardíaca (IC) e fraqueza da musculatura inspiratória (FMI) apresentam limitação na realização de atividades da vida diária devido à dispnéia e cansaço. Objetivo. Avaliar em pacientes com miocardiopatia hipertensiva e FMI o efeito do treinamento da musculatura inspiratória (TMI) sobre a força e resistência dos músculos respiratórios, bem como na atividade simpática, hemodinâmica e a qualidade de vida. Métodos. Vinte e sete pacientes foram alocados em seqüência em dois grupos: Grupo Controle (não realizavam o treinamento) e Grupo TMI. Os pacientes incluídos no Grupo TMI participaram de um programa de exercícios respiratórios com o Threshold Inspiratório durante 12 semanas, sete sessões por semana com duração de 30 minutos por sessão, com carga de $30 \%$ da pressão inspiratória máxima $\left(\mathrm{Pi}_{\text {máx }}\right)$ de repouso, ajustada mensalmente. Antes e após 12 semanas ambos os grupos foram avaliados quanto a $\mathrm{Pi}_{\text {máx }}$ de repouso, variáveis hemodinâmicas em repouso: pressão arterial sistólica (PAS) e diastólica $(P A D)$, freqüência cardíaca $(F C)$, resistência vascular periférica (RVP) e débito cardíaco (DC); capacidade funcional cardiorrespiratória: consumo de oxigênio $\left(\mathrm{VO}_{2}\right)$, quociente respiratório de produção de gás carbônico $\left(\mathrm{VCO}_{2}\right)$, limiar anaeróbio (LA), ponto de compensação respiratório (PCR) e duração da atividade física, atividade simpática nervosa periférica 
(ANSP- microneurografia) e central (variabilidade da FC- componentes LF e HF), fluxo de sangue para o antebraço (FSA) e qualidade de vida (Questionário de Minessota). Resultados. Após 12 semanas não foram encontradas alterações significativas em qualquer parâmetro avaliado nos pacientes incluídos no Grupo Controle. Nos pacientes alocados no Grupo TMI foi possível observar alterações significativas nos seguintes parâmetros: aumento da $\mathrm{Pi}_{\text {máx }}$ (basal $59,2 \mathrm{cmH}_{2} \mathrm{O} \pm 4,9$ vs pós $\left.87,5 \mathrm{cmH}_{2} \mathrm{O} \pm 6,5\right)$; aumento do $\mathrm{VO}_{2}$ pico $(14,4$ $\mathrm{ml} / \mathrm{kg} / \mathrm{min} \pm 1,0 \mathrm{vs} 18,9 \mathrm{ml} / \mathrm{kg} / \mathrm{min} \pm 1,16) ;$ diminuição do $\mathrm{VE} / \mathrm{VCO}_{2}$ pico $(35,8$ $\mathrm{ml} / \mathrm{kg} / \mathrm{min} \pm 0,4$ vs $32,5 \mathrm{ml} / \mathrm{kg} / \mathrm{min} \pm 0,8)$; diminuição do componente LF em valor absoluto $\left(607,2 \mathrm{mms}^{2} \pm 153,9\right.$ vs $\left.263,5 \mathrm{mms}^{2} \pm 53,6\right)$, e do componente LF em valor normalizado $\left(6,2 \mathrm{mms}^{2} \pm 1,7\right.$ vs $\left.5,0 \mathrm{mms}^{2} \pm 1,1\right)$ e aumento do componente HF em valor absoluto $\left(48,41 \mathrm{mms}^{2} \pm 4,4\right.$ vs $\left.56,7 \mathrm{mms}^{2} \pm 4,4\right)$; diminuição da ANSP (37,1 \pm 3 disparos /min. vs $29,5 \pm 2,3$ disparos por minuto) e diminuição na pontuação nos domínio físico $(20,2$ pontos $\pm 3,5$ vs 7,6 pontos $\pm 2,2)$ e geral $(23,6$ pontos $\pm 3,8$ vs 9,2 pontos $\pm 2,4)$ do Questionário de Minessota. Conclusão. O TMI correlacionou-se com o aumento de força e resistência dos músculos respiratórios, melhora da capacidade cardiorrespiratória, diminuição da atividade simpática cardíaca e periférica, acarretando uma melhora na qualidade de vida de pacientes com IC hipertensiva. O TMI pode ser considerado um método seguro, prático e eficaz e uma alternativa no tratamento de pacientes com IC de etiologia hipertensiva.

Descritores: músculos respiratórios, insuficiência cardíaca, sistema nervoso autônomo e qualidade de vida. 
Mello, P.R Effect of inspiratory muscle training on the hemodynamics, sympathetic activity and quality of life of patients with hypertensive cardiomyopathy. São Paulo: School of Medicine, University of São Paulo, São Paulo, Brazil; 2009.

Background: Patients with heart failure and inspiratory muscle weakness (IMW) experience limitations in performing their routine activities due to dyspnea and fatigue. Methods and Results: Twenty-seven patients were sequentially allocated to one of two groups: a control group in which inspiratory muscle training (IMT) was not provided and the IMT group. Patients included in the IMT group participated in a program of respiratory exercises with inspiratory threshold loading consisting of seven 30-minute sessions a week for a period of 12 weeks, with a monthly increase of $30 \%$ in maximal inspiratory pressure $\left(\mathrm{Pi}_{\max }\right)$ at rest. Prior to and following the 12-week evaluation period, both groups were assessed for $\mathrm{Pi}_{\max }$ measured at rest; oxygen consumption $\left(\mathrm{VO}_{2}\right)$, ratio of ventilation to carbon dioxide production $\left(\mathrm{VE} / \mathrm{VCO}_{2}\right)$, peripheral and cardiac nervous sympathetic activity, and quality of life. Results: In the patients allocated to the IMT group, significant alterations were recorded: an increase in $\mathrm{Pi}_{\max }\left(59,2 \pm 4,9 \mathrm{cmH}_{2} \mathrm{O}\right.$ at baseline compared to $87,5 \pm 6,5 \mathrm{cmH}_{2} \mathrm{O}$ following therapy),; an increase in peak oxygen consumption $(14,4 \pm 1,03$ versus $18,9 \pm 1,16 \mathrm{ml} / \mathrm{kg} / \mathrm{min})$; a reduction in peak $\operatorname{VE} / \mathrm{VCO}_{2}(35,8 \pm 0,4$ versus $32,5 \pm 0,8 \mathrm{ml} / \mathrm{kg} / \mathrm{min})$, a reduction in the low-frequency (LF) component $\left(6,18 \pm 1,7\right.$ versus $\left.5,04 \pm 1,1 \mathrm{mms}^{2}\right)$ and an increase in the normalized value of the high frequency (HF) component $(48,4 \pm 4,4$ versus $56,7 \pm$ $\left.4,4 \mathrm{mms}^{2}\right)$, a reduction in peripheral sympathetic activity $(37,1 \pm 3$ versus $29,5 \pm$ 2,3 bursts/minute) and a reduction in the physical domain (20,2 $\pm 3,5$ versus $7,6 \pm$ 
2,2 points) and general scores (23,6 $\pm 3,8$ versus $9,2 \pm 2,4$ points) of the Minnesota instrument. Conclusion: IMT is associated with an increase in respiratory muscle strength and endurance, an improvement in cardiorespiratory capacity and a reduction in central and peripheral sympathetic activity, resulting in an improvement in the quality of life of patients with hypertensive heart disease.

Descriptors: inspiratory muscle weakness; heart failure; sympathetic activity and quality of life. 


\section{INTRODUÇÃO}

A disfunção muscular inspiratória tem um papel importante na limitação ao exercício em pacientes com Insuficiência Cardíaca (IC), no entanto, seus mecanismos ainda não estão bem esclarecidos. A intolerância ao exercício manifesta-se através de sintomas como dispnéia e fadiga da musculatura respiratória.

Em pacientes com IC, a detecção de uma menor pressão inspiratória máxima $\left(\mathrm{Pi}_{\mathrm{máx}}\right)^{1,2}$, juntamente com a resposta ventilatória inadequada durante 0 exercício ${ }^{3,4}$ reforça a afirmação de que o sistema respiratório participa na limitação da capacidade funcional nestes pacientes. A diminuição da capacidade funcional não é somente conseqüência da alteração musculoesquelética, pode estar relacionada também a alterações histológicas e fisiopatológicas.

Dentre as alterações histológicas e fisiopatológicas destacam-se: aumento do diâmetro dos capilares alveolares, edema alveolar, acúmulo de líquido no espaço pleural e intersticial, dilatação dos linfonodos; e alterações intrínsecas da musculatura respiratória como: descondicionamento muscular, má nutrição, diminuição da perfusão muscular, ativação de ergorreceptores ${ }^{5,6}$ e diminuição da complacência pulmonar.

Vem sendo demonstrado na literatura que a atividade aeróbia regular diminui a atividade simpática de pacientes com IC, dentre outras afecções que alteram o sistema nervoso autonômico (SNA) ${ }^{7}$. É possível que o treinamento da musculatura inspiratória (TMI) apresente benefícios no controle cardiovascular por 
modular a atividade autonômica reflexa nestes pacientes, tornando-se um adjuvante na melhora da qualidade de vida.

Leith e Bradley ${ }^{8}$ foram os primeiros a discutir um programa de TMI. Usualmente, o TMI está indicado para doenças como: doença pulmonar obstrutiva crônica, asma, e em situações como em desmame difícil da ventilação mecânica4, 9,10 .

Com relação à IC, a indicação da TMI como intervenção terapêutica pode ser adotada, visando melhorar a força e a resistência desses músculos em pacientes que apresentem diminuição da força dos músculos inspiratórios e IC 4,11. Recentemente, Dal'Lago e cols. ${ }^{12}$ demonstraram em ensaio clínico, randomizado, que o TMI aumenta a força muscular inspiratória, acarretando melhor qualidade de vida nestes pacientes.

A literatura é escassa quanto ao papel do TMI no controle autonômico e cardiovascular em pacientes com IC. Desta forma, o presente estudo objetiva testar a hipótese de que o TMI em pacientes com IC hipertensiva pode aumentar a força e resistência da musculatura respiratória por mecanismos associados à diminuição da atividade simpática, central e periférica acarretando melhora na qualidade de vida destes pacientes. 


\section{REVISÃO BIBLIOGRÁFICA}

\subsection{Insuficiência cardíaca - definição e epidemiologia}

A IC representa uma síndrome caracterizada por anormalidades na função e regulação neurohormonal do ventrículo esquerdo, que é acompanhada por intolerância aos esforços, retenção hídrica e diminuição da expectativa de vida ${ }^{13}$.

A Organização Mundial da Saúde definiu a insuficiência cardíaca (IC) como uma das prioridades entre as enfermidades crônicas que necessitam de estratégia especial de prevenção primária e tratamento em todo o mundo.

A IC é definida por um estado fisiopatológico no qual uma anormalidade da função cardíaca é responsável pela falência do coração em bombear sangue numa taxa compatível com a demanda metabólica tecidual do organismo, ou que o faça ás custas de elevação das pressões de enchimento das câmaras cardíacas ${ }^{14,15}$. Existem várias causas associadas ao desenvolvimento da Síndrome da IC, segundo dados do estudo de Framingham ${ }^{16}$, a causa mais freqüente da IC é a hipertensão arterial sistêmica. Entretanto, dados de estudos multicêntricos identificam a doença isquêmica como a etiologia mais freqüente, responsável por aproximadamente $70 \%$ dos casos ${ }^{17}$.

Os achados físicos da IC podem retratar manifestações sistêmicas e pulmonares, bem como hipoperfusão tecidual pela diminuição do débito cardíaco $^{14}$.

Inicialmente o prognóstico desta síndrome é ruim, com média de sobrevida, após a instalação dos sintomas, de somente 1,7 anos em homens e 3,2 anos em 
mulheres $^{15,16}$. Com a evolução da terapia medicamentosa os pacientes obtiveram melhora no prognóstico. A terapêutica da IC tem por objetivo a melhora dos sintomas, redução da mortalidade, diminuição dos custos hospitalares e prevenção de readmissões ${ }^{18}$.

Aproximadamente 23 milhões da população mundial são portadores de IC. A prevalência de IC nos países desenvolvidos como Estados Unidos é de 1 - $2 \%$ 17. No Brasil segundo o DATASUS, Ministério da Saúde, pode-se estimar que cerca de 6,4 milhões de brasileiros sofram de $I^{18}{ }^{18}$.

Aproximadamente dois milhões de casos novos de IC são diagnosticados no mundo por ano. Em contraste com outras doenças cardíacas, que vem apresentando declínio nas últimas décadas, a incidência de IC está estável ou aumentando na maioria dos países ${ }^{19}$. No Brasil não existem dados epidemiológicos que permitam definir a incidência de IC na população. Tornou-se evidente que a prevalência da IC aumenta com a idade, sendo que menos de $30 \%$ das pessoas idosas sobrevivem seis anos após sua internação por IC, o que deixa claro seu prognóstico ruim.

\subsection{Mecanismos fisiopatológicos da IC}

As repercussões funcionais da IC variam enormemente e dependem de vários fatores, incluindo idade, extensão, velocidade do desenvolvimento do déficit da função cardíaca, etiologia, causas precipitantes da IC e câmaras específicas envolvidas no processo fisiopatológico ${ }^{22}$. As alterações funcionais são conseqüência do inadequado débito cardíaco e/ou acúmulo de sangue nos 
ventrículos frente à necessidade do organismo para determinada atividade ${ }^{22}$, que são a base para a chamada teoria da pressão anterógrada e retrógada da IC: 1) aumento da pressão e volume diastólico final do ventrículo; 2) aumento da pressão e volume do átrio correspondente ao ventrículo insuficiente; 3) contração atrial mais vigorosa (mecanismo de Starling) ${ }^{23}$; 4) aumento de pressão nos leitos venosos e capilares; 5) aumento da transudação de líquidos do capilar para o interstício. Muitos dos sintomas da IC são conseqüentes a esta seqüência de eventos e resultante dos fluídos no espaço intersticial nos pulmões.

Após a instalação da disfunção cardíaca, a maioria dos pacientes pode permanecer assintomática por períodos de tempo variáveis em decorrência da ativação de mecanismos adaptativos utilizados para atenuar a diminuição do DC e manter a oferta de nutrientes para os tecidos e células. Dentre os mecanismos adaptativos destaca-se a ativação do sistema renina angiotensina - aldosterona (SRAA) e o sistema nervoso simpático (SNS). Estas adaptações iniciam-se rapidamente e são capazes de sustentar ou modular a função ventricular em níveis próximos do normal por períodos variáveis de tempo ${ }^{24}$.

A versão clássica dos mecanismos de ativação dos sistemas é a redução volume circulante efetivo, detectado pelos barorreceptores carotídeos e aórticos, que leva ao aumento da atividade simpática de forma generalizada tendo como conseqüência, vasoconstrição periférica, aumento da resistência vascular e retenção de sódio e água ${ }^{16,25,26}$. Na IC ocorre aumento da produção de renina por meio da estimulação dos receptores beta adrenérgicos, secundário ao aumento da atividade simpática; a renina atua sobre o angiotensinogênio transformando-o em angiotensina I, que é convertido em angiotensina II pela enzima de conversão da 
angiotensina (ECA) ${ }^{26}$. A ação da angiotensina II sobre os vasos produz vasoconstrição e contribui junto ao SNS para a elevação da resistência vascular, pois facilita a liberação de noradrenalina pelo sistema simpático e estimula a secreção de aldosterona pela glândula supra-renal, aumentando a reabsorção de sódio no nível do túbulo distal. Outras substâncias que participam dos mecanismos fisiopatológicos da IC, como: vasopressina e endotelina ${ }^{16}$.

A partir do momento em que os mecanismos adaptativos tornam-se insuficientes, ocorre o desenvolvimento de sintomas e manifestações clínicas, dentre eles, a incapacidade diante do esforço físico que se caracteriza pela dispnéia ao esforço. A gravidade da IC pode estar associada ao grau de dificuldade ao esforço, sendo a classificação funcional da New York Heart Association (NYHA) ${ }^{27}$ a mais utilizada nas Diretrizes Brasileiras.

Vem sendo demonstrado na literatura que a atividade aeróbia regular diminui a atividade simpática em pacientes com HAS e IC, dentre outras afecções do sistema nervoso autônomo ${ }^{7}$. Roveda e colaboradores ${ }^{7}$ descreveram uma forte correlação entre o aumento da atividade simpática e aumento da disfunção ventricular. Os autores demonstraram por microneurografia que, pacientes com IC quando submetidos a exercício aeróbio, apresentam diminuição da atividade simpática nervosa em repouso, apresentando semelhança com o resultado encontrado em indivíduos controle ${ }^{7}$.

A origem do aumento da descarga simpática, durante o exercício aeróbio e em repouso na IC, tem sido atribuída a duas classes de mecanismos neurais ${ }^{28}$ : A primeira envolve a ativação direta das áreas motoras, ventilatórias do sistema nervoso central pelas vias cerebrais, que ocorrem no início do exercício ${ }^{28}$. 
A segunda envolve uma rede de reflexos que podem ativar as áreas ventilatórias e de controle cardiovascular por meio das aferências musculares localizadas em território pulmonar e cardíaco ${ }^{29}$. As aferências do tipo III e IV presentes na musculatura esquelética são ativadas no início do exercício são denominadas ergorreceptores sendo estimulados pelo trabalho muscular ${ }^{30}$. Os ergorreceptores são divididos em: mecanorreceptores (sensíveis à deformação mecânica das unidades músculo tendinosas e pela distensão venosa) e metaborreceptores (sensíveis ao acúmulo de metabólitos relacionados ao trabalho muscular) ${ }^{30}$. A ativação de aferências pode modificar reflexamente a freqüência cardíaca, a pressão arterial, o débito cardíaco, o volume sistólico, a ventilação e a atividade simpática, porém sua ação é predominante no leito vascular sistêmico 31,32

Estudos em animais demonstraram que a presença de fadiga diafragmática associa-se ao aumento da atividade dos ergorreceptores de fibras frênicas aferentes de pequeno diâmetro e de fibras tipo IV ${ }^{33,34}$. A estimulação elétrica ou farmacológica de fibras frênicas aferentes em animais (injeções de ácido lático provocando isquemia muscular diafragmática) leva ao aumento da atividade simpática em conjunto com a resistência vascular em muitos leitos vasculares, incluindo a musculatura periférica, sistema renal e vasos coronários 35,36

Outro reflexo respiratório é desencadeado por receptores de estiramento pulmonar que podem modular a resposta simpática, decorrente da atividade de barorreceptores. Estudos em humanos que utilizaram manipulação da pressão do seio carotídeo (colar cervical - neck chamber) mostraram que a sensibilidade do 
sistema nervoso simpático sob influência dos barorreceptores flutua durante a ventilação com maior amplitude em baixos volumes pulmonares, onde a atividade simpática é maior ${ }^{37,38,39}$. Da mesma forma, as variações da pressão intratorácica e da pressão transmural podem afetar indiretamente os barorreceptores aórticos ${ }^{37}$. O maior ou o menor grau de atividade desses receptores determina a atividade simpática periférica ${ }^{37}$. Flutuações na atividade simpática durante a ventilação se direcionam a pequenas variações na pressão sanguínea sistêmica e no volume pulmonar ${ }^{40}$. A modulação ventilatória pela atividade nervosa simpática aumenta conforme alterações no volume corrente, com sensibilidade ao aumento do volume pulmonar expiratório final ${ }^{41}$.

Outro fator importante na atividade simpática na IC, para o coração e periferia é a influência dos mecanorreceptores ventriculares, sensíveis á pressão de enchimento ventricular dependente do retorno venoso ${ }^{37}$.

Trabalhos prévios em nosso laboratório demonstraram que pacientes com HAS e IC apresentam alterações autonômicas do controle reflexo cardiorrespiratório, evidenciadas por diferentes metodologias, que podem ter impacto negativo no prognóstico dos pacientes. Otto e cols ${ }^{42}$, avaliando pacientes hipertensos com IC, demonstraram que a modulação aguda de volume de baixa intensidade (diminuição do retorno venoso por meio da aplicação de pressão negativa nos membros inferiores) não se acompanha do esperado ajuste no fluxo de sangue para a musculatura esquelética, sugerindo que 0 reflexo cardiopulmonar que está comprometido neste grupo de pacientes. Por meio do mesmo método (modulação aguda de volume), de Carvalho e cols. ${ }^{43}$ evidenciaram que existem significativas alterações do intervalo QT associado a 
mudanças no volume intracardíaco em pacientes idosos com IC, sugerindo que a modulação de volume sobre a estabilidade elétrica cardíaca. Ainda, Rodrigues Sobrinho e cols. ${ }^{44}$ avaliaram a resposta de pacientes hipertensos com IC a hipóxia e a hiperóxia (estudo do quimiorreflexo). Ficou evidente a exacerbação da resposta ventilatória e maior ativação do sistema nervoso simpático (aumento da noradrenalina sérica e menor vasodilatação periférica) durante a hipóxia; ocorreu maior resposta autonômica a hipercapnia, o que sugere uma maior excitabilidade do quimioreflexo central. Nos estudos descritos, o controle da atividade simpática, avaliado pela dosagem de noradrenalina plasmática, mostrou-se também comprometido. Dados mais recentes focando a análise da variabilidade da freqüência cardíaca, reconhecido marcador de prognóstico na IC, evidenciaram que diferentes grupos de pacientes com cardiomiopatia hipertensiva, disfunção distólica, e disfunção diastólica mais sistólica, apresentavam aumento da atividade simpática e menor atividade parassimpática para o coração na situação de repouso, comparado com indivíduos normais ${ }^{45}$.

De modo interessante, durante a modulação aguda de volume, os grupos se comportam de maneira oposta: enquanto ocorre melhora do desequilíbrio autonômico no grupo com IC diastólica e sistólica (diminuição da atividade simpática e aumento da atividade parassimpática), o grupo com IC diastólica não apresentou tal benefício ${ }^{46}$. $\mathrm{O}$ aumento da atividade simpática descrita acima pode ser também demonstrado por meio da técnica de microneurografia. Podemos levantar a hipótese de que o aumento da atividade simpática observada em pacientes com IC tem intensa relação com alterações no controle reflexo em resposta à modulação de volume intratorácico (reflexo cardiopulmonar) e em 
resposta a estímulos respiratórios (quimiorreflexo), e que a ação sobre essas variáveis pode ter um impacto benéfico na modulação da atividade simpática ${ }^{46}$.

\subsection{Manifestações clínicas}

A dispnéia é considerada a principal manifestação clínica da IC e é definida como uma experiência subjetiva de desconforto respiratório, que consiste de sensações qualitativamente distintas, variáveis em sua intensidade. A experiência deriva de interações entre múltiplos fatores fisiológicos, psicológicos, sociais e ambientais podendo induzir respostas comportamentais e fisiológicas secundárias 47,48. Os mecanismos responsáveis pela dispnéia não estão completamente esclarecidos. Inicialmente o aparecimento da dispnéia está relacionado à execução de atividade física; sendo a classificação funcional da New York Heart Association (NYHA) a mais utilizada nas Diretrizes Brasileiras ${ }^{27}$.

\begin{tabular}{|l|l|}
\hline Classe 1 & $\begin{array}{c}\text { Pacientes com cardiopatia, mas sem limitações resultantes da } \\
\text { atividade física. A atividade física comum não causa fadiga anormal, } \\
\text { palpitações ou dor anginosa. }\end{array}$ \\
\hline \hline Classe 2 & $\begin{array}{l}\text { Pacientes com cardiopatia levando a leve limitação da atividade física. } \\
\text { Assintomáticos em repouso. A atividade física comum resulta em fadiga, } \\
\text { palpitação, dispnéia ou dor anginosa. }\end{array}$ \\
\hline \hline
\end{tabular}




\begin{tabular}{|l|l|}
\hline Classe 3 & $\begin{array}{l}\text { Pacientes com cardiopatia resultando em marcada limitação de } \\
\text { atividade física. Assintomáticos em repouso. Mínimo esforço físico, } \\
\text { menos que a atividade física comum, causa fadiga, palpitação, dispnéia } \\
\text { ou dor anginosa. }\end{array}$ \\
\hline Classe 4 & $\begin{array}{l}\text { Pacientes com cardiopatia incapazes de executar qualquer atividade } \\
\text { física sem desconforto. Os sintomas de Insuficiência Cardíaca ou de } \\
\text { Síndrome Anginosa podem estar presentes mesmo em repouso. A } \\
\text { qualquer esforço físico empreendido o desconforto aumenta. }\end{array}$ \\
\hline \hline
\end{tabular}

Alterações pulmonares no paciente com IC são fatores importantes na determinação da dispnéia, principalmente as de origem histopatológicas e hemodinâmicas 49,50,51, incluindo aumento no diâmetro dos capilares alveolares, edema alveolar, acúmulo de líquido no espaço pleural e intersticial, acarretando uma dilatação nos linfonodos ${ }^{51}$. As veias pulmonares tornam-se dilatadas causando remodelamento do vaso; as veias brônquicas ficam congestas e dilatadas devido ao aumento do fluxo sangüíneo nas anastomoses broncopulmonares ${ }^{51}$. Como conseqüência do aumento da pressão peribrônquica, o diâmetro dos bronquíolos diminui resultando em maior resistência á passagem de $\operatorname{ar}^{52}$. Os receptores $\mathrm{J}$, de pequeno calibre, localizados no interstício alveolar, são ativados promovendo um reflexo broncoconstritor em resposta a edema intersticial $^{52}$. 
Pacientes com alterações em testes pulmonares demonstram alterações na mecânica respiratória, havendo diminuição do volume pulmonar, da complacência e aumento da resistência das vias aéreas; as alterações na mecânica respiratória acarretam aumento do trabalho respiratório e, como conseqüência, a dispnéia ${ }^{51}$. Pacientes com IC possuem uma diminuição da capacidade pulmonar total (CPT) capacidade vital (CV) e aumento na relação entre volume expiratório forçado no primeiro segundo e capacidade vital forçada (VEF/CVF), ${ }^{53,54}$. O componente restritivo deve-se primariamente á diminuição do volume pulmonar, e secundariamente ao aumento cardíaco, aumento alveolar, fluído intersticial e a formação de derrame pulmonar ${ }^{54}$.

Devido à diminuição na capacidade pulmonar total (CPT) o volume residual (VR) pode estar aumentado devido ao "air trapping" causado pelo fechamento prematuro das pequenas vias aéreas ${ }^{55}$. O fenômeno do "air trapping" explica a discrepância no volume pulmonar na IC, que pode ser obtido pela técnica de pletimosgrafia (valor aumentado) e pela técnica de diluição de gás inerte respectivamente (valor aumentado) ${ }^{56}$. Light e George estudaram 28 pacientes com quatro dias de admissão por descompensação aguda decorrente da IC ${ }^{60}$. Como resultado obteve-se diminuição da CVF (57\% do previsto) e diminuição da relação $V E F_{1} / C V F{ }^{57}$. O VR foi considerado alto sugerindo significante air traping ${ }^{57,51}$.

Outra teoria para o mecanismo de dispnéia envolve a inadequação da relação comprimento - tensão dos músculos respiratórios. Propôs-se que quando ocorre desalinhamento de feixes musculares, ocorre uma sensação de inspiração insuficiente para a tensão gerada pelos músculos respiratórios ${ }^{58}$. 
Nos últimos 25 anos, houve um grande avanço no conhecimento da fisiopatologia da IC ${ }^{49}$, permitindo demonstrar alterações estruturais, funcionais e metabólicas do sistema músculo esqueléticas, respiratórias e nervosas, junto com as do sistema cardiovascular ${ }^{48,50 .}$

A base das alterações intrínsecas na musculatura respiratória permanece sem resposta ${ }^{59}$. Possíveis mecanismos incluem: descondicionamento, má nutrição que afeta o peso e a histoquímica muscular, diminuição perfusional, inadequação da relação comprimento/tensão e alterações neurohormonais como: elevado nível de cortisol, catecolaminas e fator de necrose, que interferem na mecânica respiratória, levando a fraqueza da musculatura respiratória acarretando a dispnéia ${ }^{51,58}$.

A fraqueza da musculatura ventilatória, freqüentemente encontrada em pacientes com IC ${ }^{12}$, pode estar também implicada na sensação da dispnéia (23) Mancini e cols. ${ }^{60}$ demonstraram hipóxia na musculatura inspiratória durante 0 exercício físico em pacientes com IC, sugerindo a presença de baixa perfusão da musculatura. Esta hipóxia aumenta o trabalho do diafragma, causando fadiga precoce.

Nishimura e cols. mensuraram a força da musculatura respiratória, consumo de $\mathrm{O}_{2}$ e hemodinâmica de 23 pacientes com IC 63. A Pi $\mathrm{I}_{\text {máx }}$ mostrou-se diminuída em pacientes classe funcional III e IV ${ }^{61}$. Hammond e cols. compararam a força e endurance da musculatura respiratória e dos membros inferiores de dezesseis pacientes com IC e quatorze indivíduos controle ${ }^{62}$. O resultado demonstrou que houve diminuição acentuada de força e endurance na musculatura respiratória em relação aos membros inferiores destes pacientes ${ }^{62}$. 
A tentativa de explicar os mecanismos que envolvem o decréscimo de força e resistência muscular respiratória em pacientes com IC tem sido baseada em testes de função pulmonar comparando indivíduos normais e pacientes com IC. A ventilação voluntária máxima e a capacidade ventilatória sustentada máxima estão reduzidas em pacientes IC comparadas ao grupo de indivíduos normais, sugerindo que a capacidade ao exercício físico por período prolongado encontra-se diminuída ${ }^{63}$. A capacidade ventilatória máxima sustentada em indivíduos normais é de aproximadamente $90 \mathrm{l} / \mathrm{min}$, em pacientes IC, o índice é de até $501 / \mathrm{min}^{64}$. Da mesma forma, a força da musculatura respiratória, mensurada por meio de testes de inspiração e expiração máxima mostrou-se estar diminuído na IC ${ }^{65}$. Forgiarini e cols. demonstraram diminuição da pressão expiratória máxima em pacientes IC de classe funcional II em relação à classe funcional III por meio da manovacuômetria 66.

Indiretamente, a fadiga diafragmática pode influenciar o desempenho na atividade física pelo aumento do uso de musculatura acessória, que leva a uma deformação da parede torácica e ineficiência mecânica durante a ventilação necessitando de maior demanda de sangue para a musculatura ventilatória. Como já discutido, o aumento da participação dos músculos respiratórios desencadeia aumento da aferência sensorial ao sistema nervoso central, e, portanto, aumentam a sensação do esforço dos músculos respiratórios ${ }^{67,68}$. 


\subsection{Treinamento da musculatura inspiratória}

Efeitos benéficos da atividade física aeróbia regular em relação às alterações pulmonares e músculo esquelético do paciente com IC têm sido demonstrados ${ }^{69}$. Sessões de 30 minutos de atividade física aeróbia aumentam a capacidade do paciente com IC de executar exercícios, demonstrado pelo aumento de $33 \%$ de desempenho, e $9 \%$ de aumento no pico de consumo de $\mathrm{O}_{2}$ 69,70 .

Os mecanismos pelo quais se evidencia o efeito benéfico da atividade física regular no paciente com IC podem estar associados à melhora hemodinâmica, correções de alterações endoteliais (aumentando a síntese de óxido nítrico sintase e-NOS), normalização das alterações metabólicas das fibras oxidativas, aumento da expressão de miosina de fibras de contração lenta, preservação da função mitocondrial e por melhorar o controle reflexo cardiopulmonar ${ }^{71,72,73,74}$.

Devido à dificuldade que os pacientes com IC possuem de realizar atividade física aeróbia regular, o treinamento de musculatura inspiratória torna-se uma alternativa de diminuir as alterações pulmonares destes pacientes ${ }^{75}$.

Leith e Bradley foram os primeiros a discutir o uso de um programa de treinamento da musculatura inspiratória (TMI) em pacientes com IC ${ }^{8}$. O TMI tem sido considerado um potencial agente modificador das anormalidades dos músculos respiratórios com ganho de força e resistência, melhorando o sintoma de dispnéia e qualidade de vida ${ }^{8}$. Deve-se salientar que o determinante da 
necessidade de indicação do TMI, não é a doença, e sim a presença de fraqueza da musculatura inspiratória.

Para que ocorram os benefícios fisiológicos com o TMI, são necessários estímulos apropriados, respeitando-se os três princípios básicos do treinamento muscular: sobrecarga, especificidade e reversibilidade ${ }^{10}$. O princípio da sobrecarga significa que o músculo deve ser solicitado em níveis superiores ao normal para que as células musculares aumentem em tamanho (com altas intensidades e poucas repetições) ou aumentem sua capacidade funcional (com baixas intensidades e quantidades maiores de repetições) ${ }^{10}$.

O princípio da especificidade implica que somente os músculos que participam ativamente do treinamento obtêm benefícios fisiológicos ${ }^{10}$. Neste sentido o princípio de reversibilidade afirma que os efeitos do treinamento são transitórios e reversíveis, portanto quando os benefícios necessitam ser mantida, a rotina de TMI deve ser sustentada ${ }^{10}$.

Com base nestes princípios, o programa de TMI é determinado para melhorar a função muscular, devendo respeitar intensidade, duração e freqüência

O método comumente utilizado para a realização do TMI implica em um treinamento de força, com poucas repetições e uma alta carga, acarretando um aumento de força muscular e hipertrofia ${ }^{10,76}$. Para o treinamento de resistência aplicam-se muitas repetições e uma sobrecarga baixa, sendo que as adaptações que ocorrem com esta estratégia são: aumento da capacidade oxidativa, número e tamanho de mitocôndrias e na densidade capilar ${ }^{76}$. Geralmente os músculos respiratórios devem ser treinados para força e resistência, para que ocorram benefícios relacionados à hipertrofia e capacidade funcional ${ }^{76}$. 
O "Threshold inspiratório" é um equipamento utilizado para o treinamento da musculatura respiratória e corresponde a um cilindro de plástico, que contém uma válvula de fluxo de ar e um regulador interno, que controla a carga a qual o paciente tem que realizar o exercício de acordo com os valores obtidos na $\mathrm{Pi}_{\text {máx }}$, que deve manter-se entre $20 \%$ e $40 \%{ }^{4,12}$.

Embora o TMI aumente a força e resistência após treinamento apropriado, há poucas descrições sobre o impacto na melhora da capacidade funcional e da qualidade de vida em pacientes com IC relacionado com a diminuição do desconforto respiratório ${ }^{73}$. Johnson e cols. ${ }^{75}$ demonstraram em ensaio clínico, que o treinamento de musculatura inspiratória melhorou a função com ganho de $25 \mathrm{~cm} \mathrm{H} \mathrm{H}_{2} \mathrm{O}$ na força inspiratória contra $12,3 \mathrm{~cm} \mathrm{H}_{2} \mathrm{O}$ no grupo controle, porém não encontraram resultados significativos quanto à tolerância ao exercício e a qualidade de vida dos pacientes com IC ${ }^{4}$. Tais achados contrapõem-se aos estudos de Mancini e cols. que demonstraram uma melhora na qualidade de vida dos pacientes com IC, diminuição do trabalho respiratório durante atividade diária verificada através de questionários de qualidade de vida, aumento na capacidade de realização de exercício submáximo e melhora no teste de seis minutos de caminhada ${ }^{4}$. Recentemente, Dall'Ago e colaboradores demonstraram que o TMI incrementou a força dos músculos inspiratórios em $15 \%$ e o pico do consumo de oxigênio aumentou $17 \%$ em relação ao grupo controle não treinado. Ainda não existem evidências sobre o impacto do TMI na atividade simpática central e periférica $^{12}$. 


\subsection{Avaliação da capacidade cardiopulmonar}

A ergoespirometria trata-se de um método eficaz e reprodutível para avaliar as adaptações cardiopulmonares do organismo em diferentes intensidades do esforço e utiliza da análise de consumo de $\mathrm{O}_{2}$ e produção de $\mathrm{CO}_{2}$ para inferir as funções do sistema respiratório e cardiovascular. ${ }^{77}$

$\mathrm{O}$ consumo $\mathrm{VO}_{2}$ pico $\left(\mathrm{ml} \cdot \mathrm{kg}^{-1} \cdot \mathrm{min}^{-1}\right)$, pode ser definido como a capacidade do organismo de absorver oxigênio. A diminuição do $\mathrm{VO}_{2}$ pico deve-se ao $\mathrm{DC}$ reduzido associado á menor oferta de oxigênio aos músculos, o que pode causar fadiga devida á diminuição na perfusão muscular. Segundo a equação de Fick, os fatores determinantes do consumo de oxigênio são o DC e a extração periférica de oxigênio ${ }^{78}$. A relação entre o consumo $\mathrm{VO}_{2}$ pico e $\mathrm{O}$ DC confere a ergoespirometria valor prognóstico indiscutível na avaliação de pacientes com IC, sendo inclusive preditor importante para eventos e óbito ${ }^{78}$.

Quando comparados a indivíduos normais, os pacientes com IC apresentam resposta ventilatória muito aumentada durante a avaliação ergoespirométrica. Os mecanismos envolvidos na hiperpnéia são: aumento inadequado do VS ao exercício, conseqüentemente, diminuição de perfusão muscular, acúmulo precoce de ácido lático, com concomitante diminuição de bicarbonato plasmático e desequilíbrio perfusão/ventilação, reduzindo com isso a eficiência ventilatória pulmonar ${ }^{78}$.

A elevação inadequada do VS durante o exercício, e a conseqüente diminuição de oferta de oxigênio aos tecidos, prolonga o tempo de resposta do 
consumo $\mathrm{VO}_{2}$ no início do exercício. Este fato reflete a alteração do DC que, devido ao prolongamento do tempo circulatório, retarda o retorno do sangue desoxigenado da musculatura periférica. Desta forma, o $\mathrm{VO}_{2}$ pico em pacientes mais graves é observado alguns segundos após o término do teste com a diminuição da intensidade do exercício ${ }^{79}$. Em indivíduos normais após o termino do exercício $\circ \mathrm{VO}_{2}$ retorna rapidamente aos valores basais. Belardinelli e cols. ${ }^{80}$ sugerem que a redução da capacidade funcional não é conseqüência somente da redução do fluxo sangüíneo muscular esquelético e consumo de $\mathrm{VO}_{2}$ pico inadequado, o acúmulo de ácido lático no músculo e sangue durante o exercício é inversamente proporcional ao conteúdo de enzimas oxidativas musculares, contribuindo para a limitação funcional.

Gaesser e Poole ${ }^{81}$ observaram que a elevação da ventilação (VE) está associada ao aumento do trabalho mecânico e, por conseqüência, com o incremento no consumo $\mathrm{VO}_{2}$ dos músculos respiratórios. Sendo assim, acredita-se que a participação dos músculos respiratórios no consumo de $\mathrm{O}_{2}$ pode estar associada aos seguintes fatores: 1) os músculos respiratórios sustentam grandes cargas de trabalho durante o exercício intenso de carga constante. Para manter altos níveis de VE parte do DC (14\% - 16\%) é direcionada para esta musculatura; 2) a composição dos músculos ventilatórios em relação a isoforma de miosina da cadeia pesada semelhante a dos músculos periféricos ${ }^{81}$. Portanto, 0 recrutamento progressivo de fibras de concentração rápida na musculatura respiratória pode contribuir para este evento ${ }^{81}$. A adição de carga inspiratória durante o exercício não somente aumenta o trabalho dos músculos respiratórios 
como participa da modificação do trabalho cardíaco, devido às alterações na pressão intratorácica.

Sabe-se que, sob altas pressões intratorácicas, ocorre a diminuição do retorno venoso ${ }^{82}$. Por outro lado, a redução da pressão intratorácica ocasiona uma elevação da pós-carga, aumentando o trabalho cardíaco. O aumento da carga inspiratória está associado a pressões intrapleurais e subatmosférica no pico da inspiração, e justamente esse comportamento da pressão intrapleural pode facilitar o retorno venoso e diminuir o trabalho cardíaco. Porém, o efeito do DC pode ser dependente de modificações na magnitude da diferença da pressão pleural em cada ciclo ventilatório ou na variação pleural média ${ }^{82}$.

Além do consumo $\mathrm{VO}_{2}$ pico, outra variáveis disponíveis no exame de ergoespirometria principalmente o equivalente ventilatório de $\mathrm{CO}_{2}\left(\mathrm{VE} / \mathrm{VCO}_{2}\right)$, também podem auxiliar no prognóstico de eventos, sobrevida e número de internações nos pacientes com IC ${ }^{77}$. 


\section{HIPÓTESE}

Pacientes com IC de origem hipertensiva e que apresentam fraqueza da musculatura inspiratória, quando submetidos a um programa de Treinamento da Musculatura Inspiratória (TMI), podem apresentar aumento da força da musculatura inspiratória e melhora na qualidade de vida, por mecanismos associados à melhora da atividade simpática e controle cardiovascular. 


\section{OBJETIVOS}

\subsection{Objetivo geral}

Avaliar em pacientes com miocardiopatia hipertensiva e fraqueza da musculatura inspiratória o efeito do TMI sobre a força e resistência dos músculos respiratórios, bem como na atividade simpática, hemodinâmica e a qualidade de vida.

\subsection{Objetivos específicos}

Avaliar em um grupo de pacientes com miocardiopatia hipertensiva e fraqueza da musculatura inspiratória o efeito do TMI sobre:

$\checkmark \mathrm{Pi}_{\text {máx }}$ e $\mathrm{Pe}_{\text {máx }}$ (Força muscular respiratória)

$\checkmark \quad$ Variáveis hemodinâmicas em repouso (PAS, PAD, FC, RVP e DC);

$\checkmark \mathrm{VO}_{2}, \mathrm{VCO}_{2}, \mathrm{LA}, \mathrm{PCR}$ e duração da atividade física (capacidade funcional cardiorrespiratória);

$\checkmark$ Variabilidade da FC e PA e atividade simpática nervosa periférica;

$\checkmark$ Fluxo de sangue para o antebraço (perfusão tecidual);

$\checkmark$ Qualidade de vida. 


\section{CASUÍSTICA E MÉTODOS}

\subsection{Casuística}

Inicialmente foram avaliados 60 pacientes com diagnóstico de IC de origem hipertensiva provenientes do Ambulatório de Miocardiopatia e de Hipertensão do Instituto do Coração (InCor) do Hospital das Clínicas da FMUSP que apresentavam fração de ejeção $<45 \%$, (avaliado por ecocardiograma), em classe funcional II , critérios da New York Heart Association (NYHA). Desses, 27 permaneceram no estudo por preencherem os critérios de inclusão: a) fraqueza da musculatura inspiratória $\left(\mathrm{Pi}_{\operatorname{máx}}\right.$ de repouso menor que $70 \%$ do previsto); b) pacientes estáveis clinicamente c) em uso da mesma terapêutica medicamentosa nos últimos três meses. Os pacientes foram alocados seqüencialmente em dois grupos: Grupo Controle (não realizou TMI) e Grupo TMI. Ambos os grupos seguiram o protocolo descrito a seguir.

Foram excluídos pacientes com IC descompensada, doença isquêmica cardíaca ou Doença de Chagas, os pacientes fumantes e/ ou com doença pulmonar prévia. Ainda, não foram incluídos pacientes com IRC (Creatinina $>2,0$ ), Diabéticos e AVC prévio.

O protocolo de estudo foi aprovado pela Comissão Científica e de Ética do Instituto do Coração - InCor (SDC - 2565/04/185) e pelo Comitê de Ética e Pesquisa em seres humanos do Hospital das Clínicas da Faculdade de Medicina da Universidade da São Paulo - HCFMUSP (Anexo 1). 
Todos os pacientes foram informados da natureza do estudo e após concordarem em realizá-lo, assinaram o Termo de Consentimento Livre Esclarecido (Anexo 2).

\subsection{Métodos}

\subsubsection{Medida da Pressão Inspiratória Máxima ( $\left(\mathbf{P i}_{\text {máx }}\right)$.}

Para a medida da força muscular ventilatória $\left(\mathrm{Pi}_{\text {máx }}\right.$ e $\left.\mathrm{Pe}_{\text {máx }}\right)$ foi utilizado um transdutor de pressão MVD 500 V 1.1 (Microhard System, Globalmed, Porto Alegre - RS) com uma sensibilidade de $\pm 300 \mathrm{mH}_{2} \mathrm{O}$, conectado a um sistema com duas válvulas unidirecionais, uma inspiratória e outra expiratória (DHD Inspiratory Muscle Trainer), acoplado a um bucal. Os pacientes permaneceram na posição sentada, com os cotovelos apoiados e clipe nasal. Para avaliar a $\mathrm{Pi}_{\text {màx }}$ de repouso, foi solicitado que após dois ciclos respiratórios em volume de ar corrente, o indivíduo expirasse lentamente até volumes próximos ao volume residual, em seguida realizasse uma inspiração máxima contra circuito fechado. O teste foi repetido três vezes, com intervalo de um minuto entre elas, sendo considerado somente o valor máximo alcançado, desde que não houvesse uma diferença maior que $10 \%$ entre os dois maiores valores ${ }^{83}$. Um orifício de dois milímetros de diâmetro foi utilizado no sistema durante a manobra inspiratória máxima para manter a glote aberta e prevenir a produção de pressões pelos 
músculos faciais ${ }^{84}$. O valor obtido pela $\mathrm{Pi}_{\text {máx }}$ foi verificado diretamente no transdutor de pressão.

Para avaliação da $\mathrm{Pe}_{\text {máx }}$, o indivíduo era orientado a inspirar até valores próximos a capacidade vital e expirasse contra um circuito fechado. Foram realizadas três medidas com intervalo de um minuto entre cada medida, e foi considerado o maior valor de $\mathrm{Pe}_{\text {máx }} \mathrm{O}$ valor máximo alcançado. Para análise dos dados referentes à $\mathrm{Pi}_{\text {máx, }}$ usamos valores previstos de acordo com as equações propostas por Neder e Nery ${ }^{84,85}$.

FIGURA 1 - Curvas de $\mathrm{Pi}_{\operatorname{máx}}$ e $\mathrm{Pe}_{\text {Max }}$ registrados pelo manovacuômetro digital MV500

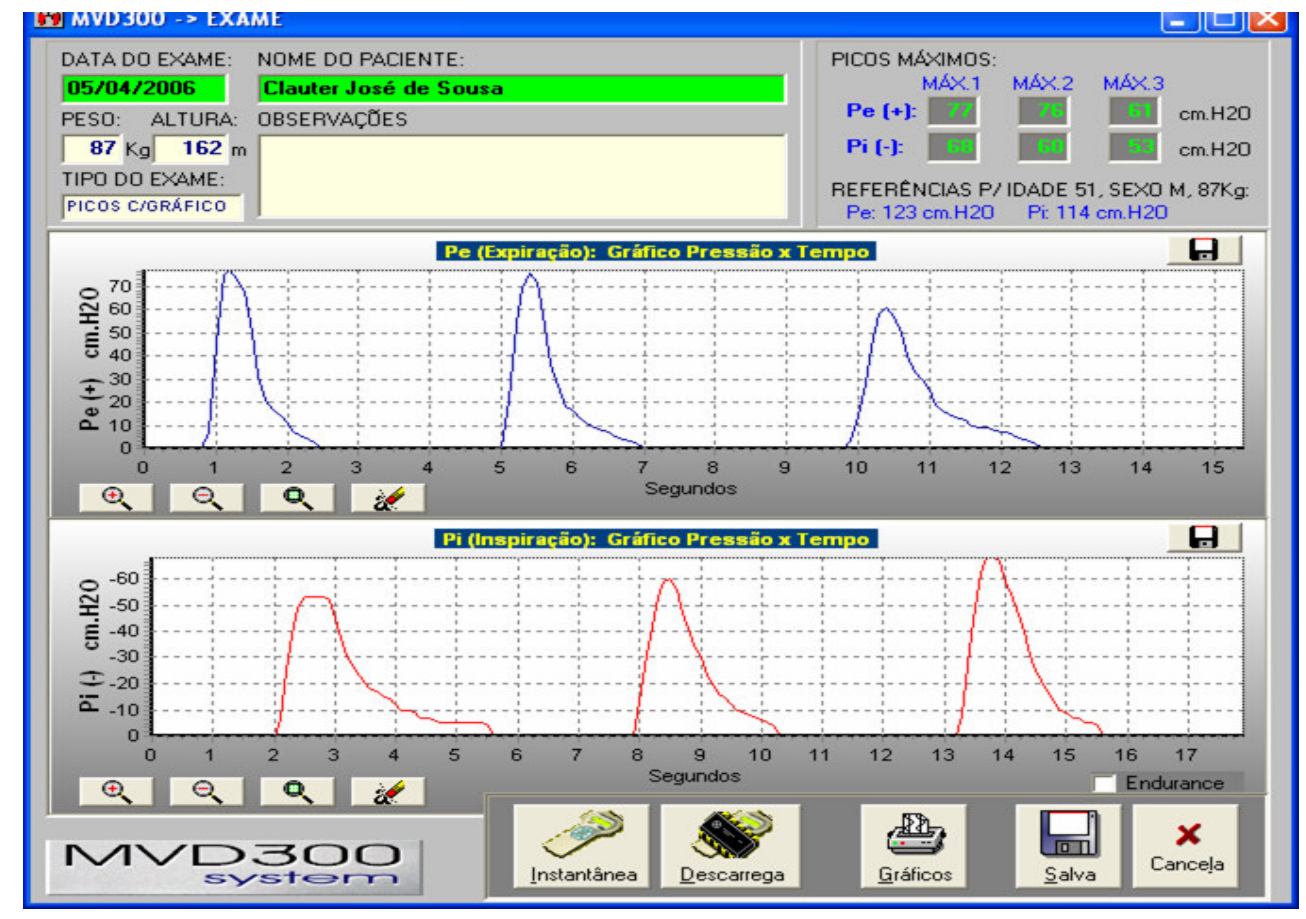




\subsubsection{Registro das variáveis hemodinâmicas pelo Finometer.}

Os registros das variáveis hemodinâmicas (pressão arterial, freqüência cardíaca, débito cardíaco e resistência vascular periférica) foram feitos durante todo o protocolo experimental, de maneira contínua batimento a batimento cardíaco. A monitorização da pressão arterial foi realizada de maneira contínua e não invasiva, com o monitor de pressão Finometer (Finometer, FMS, Finapres Medical System, Holland). O equipamento utiliza como princípio básico a técnica de fotopletismografia digital, gerando curvas de pressão arterial derivadas da pulsação da artéria digital (colocando-se um manguito de pressão circundando a falange média da mão esquerda) conforme descrito por Penaz e desenvolvido por Wesseling ${ }^{86,87,88}$. O equipamento é provido de um programa (Software BeatScope), capaz de gerar dados hemodinâmicos como pressão arterial sistólica, diastólica e média, freqüência cardíaca, débito cardíaco e resistência vascular periférica, tendo como base valores derivados da curva da pressão arterial e informações sobre idade, sexo, peso e altura.

Para o registro da freqüência cardíaca foram colocados três eletrodos no tórax do indivíduo, nas posições bipolares, para captação de sinal eletrocardiográfico na derivação CM5. Após este sinal ser pré-amplificado (General Purpose Amplifier/ Stemtech, Inc, GPA-4), ele era convertido de analógico para digital, e em seguida, armazenado para posterior análise.

Simultaneamente, as curvas de pressão arterial obtidos pelo Finometer, juntamente com o sinal do ECG foram registrados em outro 
computador provido de um sistema de aquisição e conversão de sinais biológicos AT/MCA- CODAS (DATAC Instruments Inc. Akron, Ohio, EUA). A freqüência de amostragem dos sinais foi de $1000 \mathrm{~Hz}$. Os sinais armazenados foram posteriormente submetidos a uma rotina de análises para fornecer os valores de variabilidade da freqüência cardíaca e da pressão arterial.

FIGURA 2 - Registro das variáveis hemodinâmicas pelo Finometer.

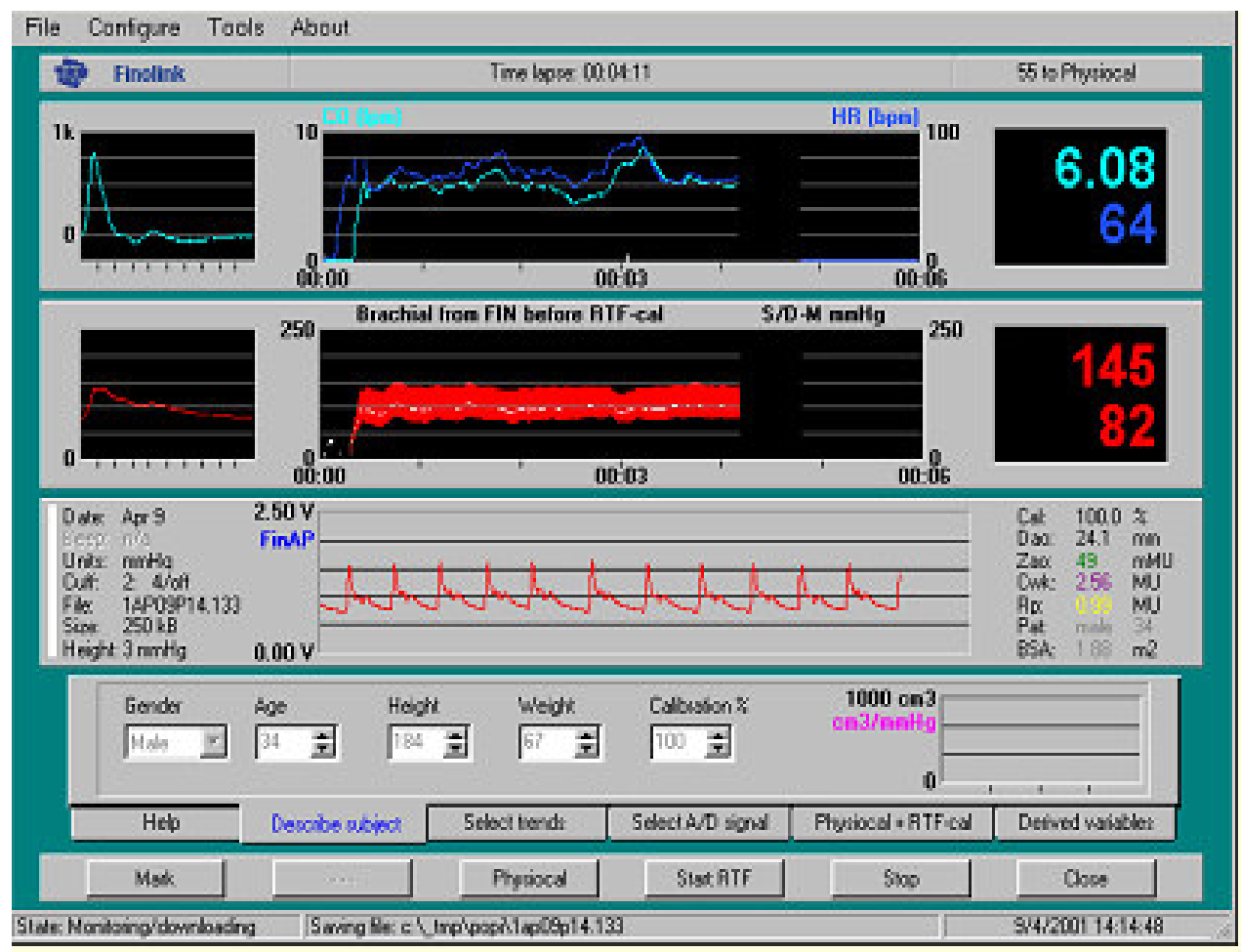

\subsubsection{Avaliação da capacidade cardiorrespiratória (ergoespirometria)}

Inicialmente, foi realizado um eletrocardiograma em repouso utilizando-se as doze derivações padrão (D1, D2, D3, AVR, AVF, V1, V2, V3, V4, V5, V6) em 
eletrocardiógrafo (Tecnologia Eletrônica Brasileira -TEB, modelo SM 310). A pressão arterial de repouso foi avaliada pelo método auscultatório, com o indivíduo na posição sentada. Subseqüentemente, os indivíduos realizaram um teste de esforço máximo em cicloergômetro eletromagnético (Medfit), seguindo o protocolo de rampa com velocidade de 60 rotações por minuto e incrementos de carga de 10,15 ou 20 Watts a cada minuto até a exaustão.

Durante o teste de esforço, o eletrocardiograma foi continuamente avaliado por meio do eletrocardiógrafo (TEB, SM 310) com três derivações simultâneas (CM5, D2 modificado e V2). A freqüência cardíaca (FC) foi registrada em repouso com indivíduo posicionado no cicloergômetro, ao final de cada minuto do teste de esforço e no $1^{\circ}, 2^{\circ}, 4^{\circ}$ e $6^{\circ}$ minutos do período de recuperação. A pressão arterial foi medida sempre pelo mesmo avaliador, em repouso, a cada 2 minutos de exercício e no $1^{\circ}, 2^{\circ}, 4^{\circ}$ e $6^{\circ}$ minutos do período de recuperação.

\section{Avaliação da capacidade funcional}

Simultaneamente ao teste de esforço, o indivíduo foi conectado a um ergoespirômetro computadorizado (CAD/Net Medical Graphics Corporation MGC, modelo 2001) por meio de um sistema de válvula e traquéia onde a ventilação pulmonar (VE) foi medida por um pneumotacógrafo a cada expiração do paciente. Por meio de sensores de oxigênio $\left(\mathrm{O}_{2}\right)$ e dióxido de carbono $\left(\mathrm{CO}_{2}\right)$ foram analisadas as concentrações de $\mathrm{O}_{2}$ e $\mathrm{Co}_{2}$ respectivamente, a cada ciclo 
respiratório. A partir da análise da VE e das concentrações de gases expirados, foram calculados o consumo de $\mathrm{VO}_{2}$ e a produção de $\mathrm{CO}_{2}$.

$\mathrm{O} \mathrm{VO}_{2}$ pico foi considerado o consumo de oxigênio obtido no pico do exercício, quando o indivíduo estava em exaustão. O quociente ventilatório de produção de gás carbônico $\left(\mathrm{VE} / \mathrm{VCO}_{2}\right)$ foi também avaliado no mesmo momento, pico do exercício.

\section{Determinação do limiar anaeróbio e ponto de compensação respiratória}

Outras variáveis que são calculadas para avaliar a capacidade funcional são Limiar Anaeróbio e Ponto de Compensação Respiratório ${ }^{77}$, 99 . Estes momentos variáveis marcam a transição do metabolismo aeróbio para o anaeróbio e sua análise é necessária para a prescrição de atividade física aeróbia. No nosso estudo, estas medidas não foram alvo de análise.

FIGURA 3 - Determinação das variáveis respiratórias obtidos com o exame de ergoespirometria.

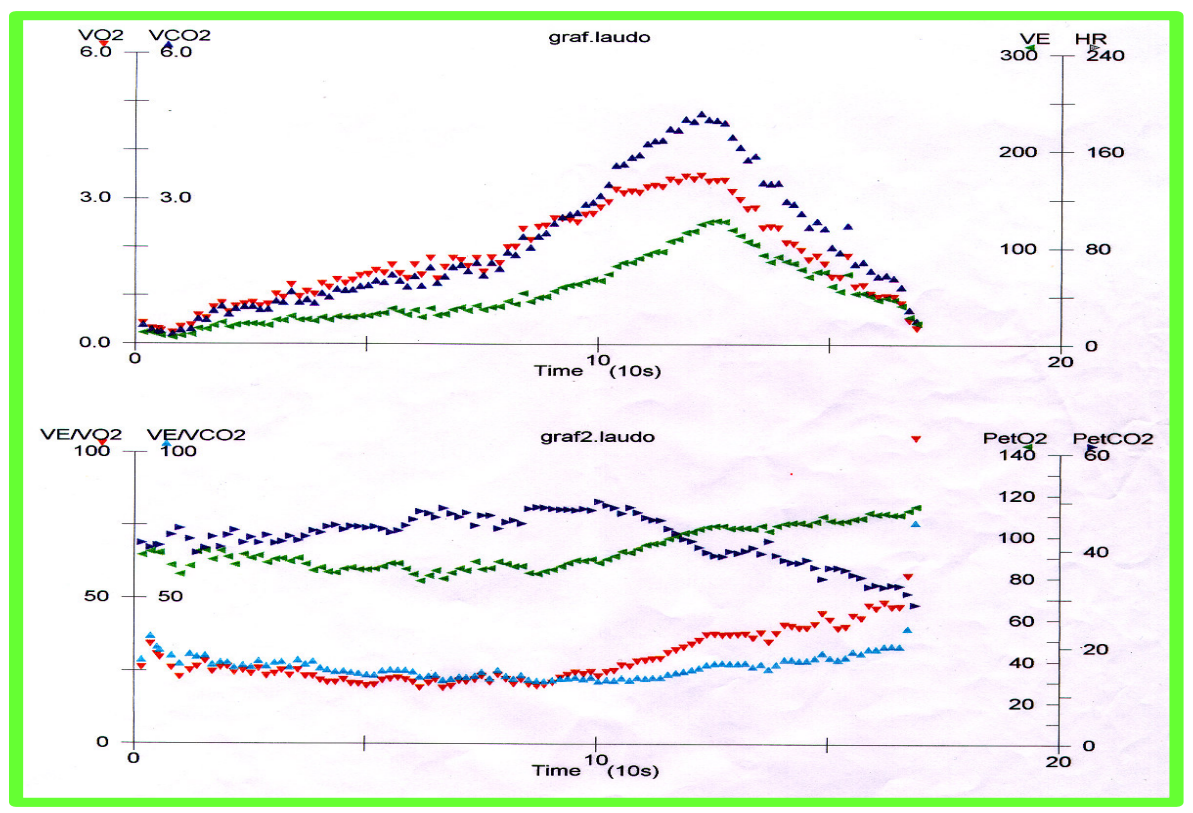




\subsubsection{Avaliação da atividade nervosa simpática periférica (ANSP) - microneurografia.}

A atividade nervosa muscular foi aferida por meio da técnica direta de registro de multiunidade da via pós - ganglionar eferente, do fascículo nervoso muscular, na parte posterior no nervo fibular, imediatamente inferior à cabeça fibular $^{90,91}$.

Os registros da atividade nervosa simpática muscular foram obtidos por meio da implantação de um microeletrodo de tungstênio no nervo fibular e de um microeletrodo referência a um centímetro do primeiro. Os eletrodos foram conectados a um pré-amplificador e o sinal do nervo foi alimentado por meio de um filtro passa-banda e, em seguida, dirigido a um discriminador de amplitude para armazenagem em osciloscópio e em caixa de som. Para fins de registro e análise, o neurograma filtrado foi alimentado por meio de um integrador de capacitância - resistência para a obtenção da voltagem da atividade neural.

A atividade simpática foi avaliada por meio de um registro contínuo da atividade simpática neuromuscular durante todo o protocolo experimental. O sinal do nervo simpático foi analisado pelo método de inspeção visual, por meio da contagem do número de descargas ocorridas por minuto, realizada por um mesmo observador para todos os pacientes. A atividade nervosa simpática muscular foi quantificada em freqüência de disparos (disparos por minuto). 
FIGURA 4 - Técnica de microneurografia - utilizada para registro da ASNP.

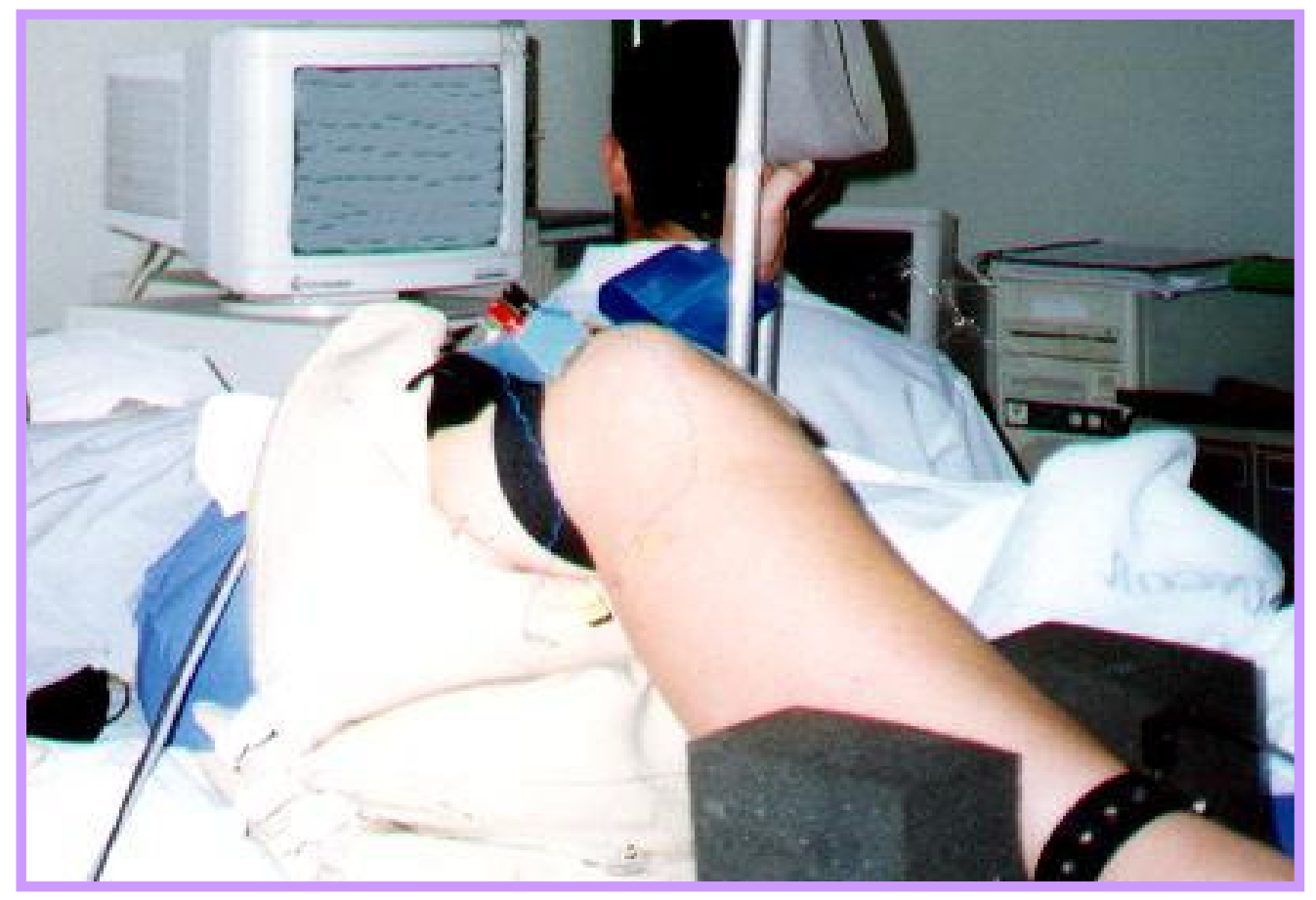

\subsection{5. - Análise da variabilidade da FC e da PA.}

Variabilidade no Domínio do Tempo: A série temporal da FC foi obtida por meio da determinação do intervalo de pulso (IP) do sinal da PA, e foi analisada no domínio do tempo por meio da análise da variância do intervalo dos batimentos normais (NN). ${ }^{94}$

Variabilidade no Domínio da Freqüência (Análise Espectral). Inicialmente realizou-se a edição manual dos sinais através da detecção dos eventos sistólicos (pico) do sinal da PAS batimento a batimento. (FIGURA 8). O intervalo de pulso (IP) foi estimado pelo intervalo entre sístoles consecutivas. Após 
inspeção visual de todas as séries obtidas fez-se a regularização da periodicidade por interpolação spline cúbica ( $(\mathrm{fi}=250 \mathrm{~Hz}$ ) e, após isto, a redução do número de pontos por decimação (18 vezes) ${ }^{94}$.

Em seguida cada batimento cardíaco foi identificado através da utilização de algoritmo através do programa Matlab ${ }^{\mathrm{MT}}$ (método de Welch), que realizou a detecção automática dos eventos sistólicos da onda de pressão, gerando o resultado final da análise espectral com as respectivas faixas de interesse.

Figura 5. Edição manual dos sinais por meio da detecção dos eventos sistólicos $($ pico $=$ seta $)$ do sinal da PAS e FC batimento a batimento, no registro obtido pelo CODAS.

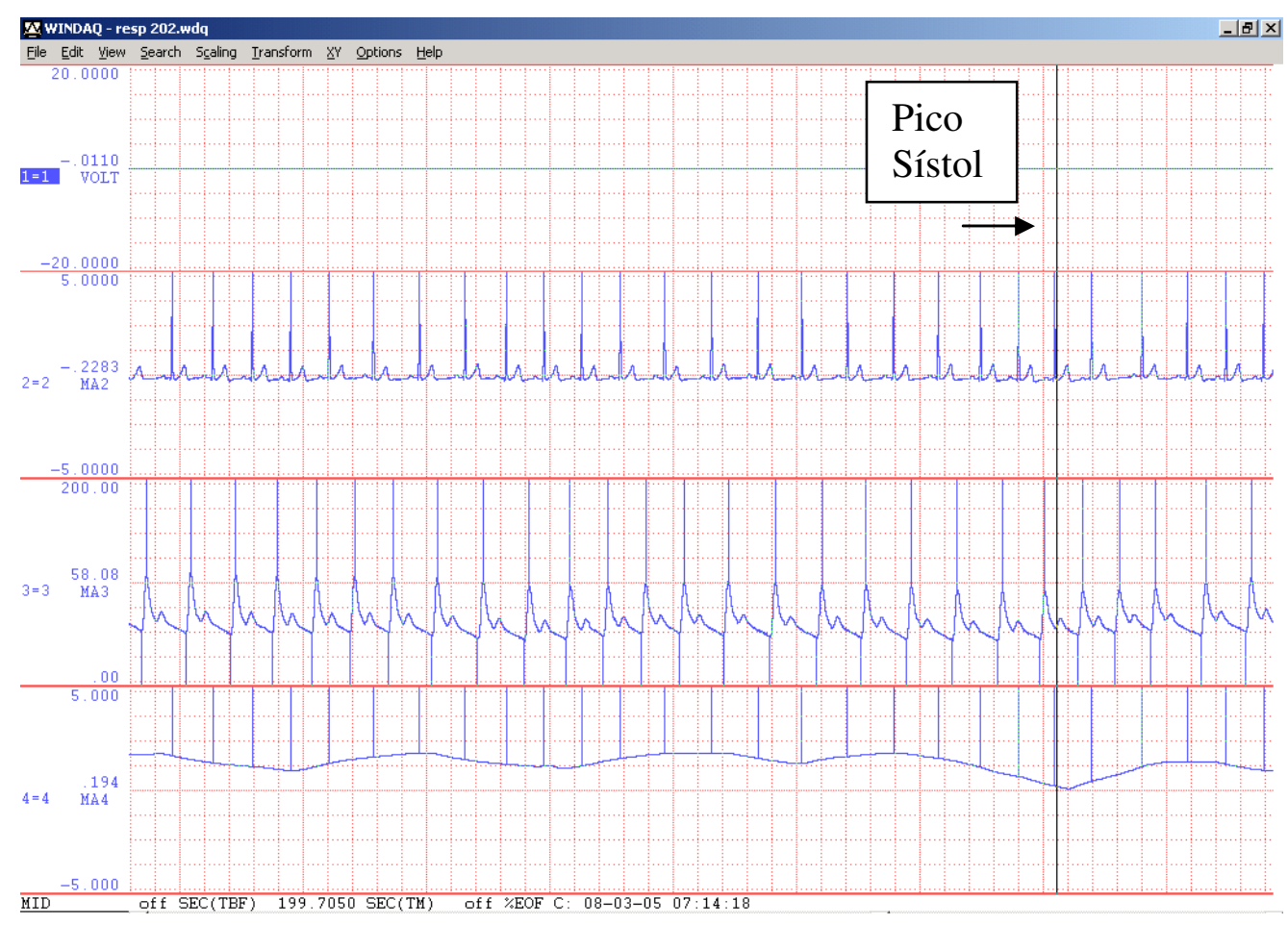


A faixa de freqüências de interesse para análise espectral no homem encontra-se no intervalo que vai de zero até em torno de 3hertz. A potência espectral foi integrada em três faixas de freqüência de interesse (HF, LF, VLF) e foi realizada a razão entre duas delas (LF/HF) para se avaliar o balanço autonômico.

- Freqüências altas (HF) entre 0,4 e 0,15 Hz-Parassimpático

- Freqüências baixas (LF) entre 0,15-0,04 Hz - Simpático

- Freqüências muito baixas (VLF) menores que 0,04 Hz.

- Balanço autonômico: LF/HF

Os componentes da variabilidade da FC no domínio da freqüência foram analisados e apresentados na sua forma normalizada (nu); ou seja:

- $L F n u=$ potência de $L F /\left(\right.$ potência total $\left.m s^{2}-V L F\right) \times 100$

- $H F n u=$ potência de $H F /\left(\right.$ potência total $\left.m s^{2}-V L F\right) \times 100$

- $L F / H F=$ relação $L F m s^{2} / H F m s^{2}$ 


\subsubsection{Pletismografia por oclusão venosa}

A pletismografia é o registro das variações de volume dos segmentos do corpo. $\mathrm{Na}$ pletismografia com a técnica de oclusão venosa, a estimativa do fluxo sanguíneo total de um segmento é feita medindo-se o aumento do volume do membro, após uma oclusão súbita e temporária do retorno venoso da região em estudo. No protocolo foi utilizado o sistema de pletismografia (Hokannson, Inc., Bellevue, WA, EUA) com sensor de estiramento (mercury strain gauges) constituído por um tubo de silicone preenchido por mercúrio, que mantém contato com eletrodos de cobre nas extremidades. Quando o sensor é colocado no antebraço do indivíduo, reflete as variações de volume que ocorrem na circunferência do membro através de mudanças de resistência registradas nos seus circuitos de ponte ${ }^{92}$.

Foram registradas no polígrafo três curvas de fluxo por minuto: no período basal, durante exercício isométrico (Handgrip) a $30 \%$ da força máxima e recuperação. O exercício isométrico consiste na realização de preensão manual em um sistema de molas (Handgrip) á 30\% da força máxima durante 3 minutos. 
FIGURA 6 - Método de Pletismografia por oclusão venosa - utilizada para obtenção do fluxo de sangue para o antebraço.

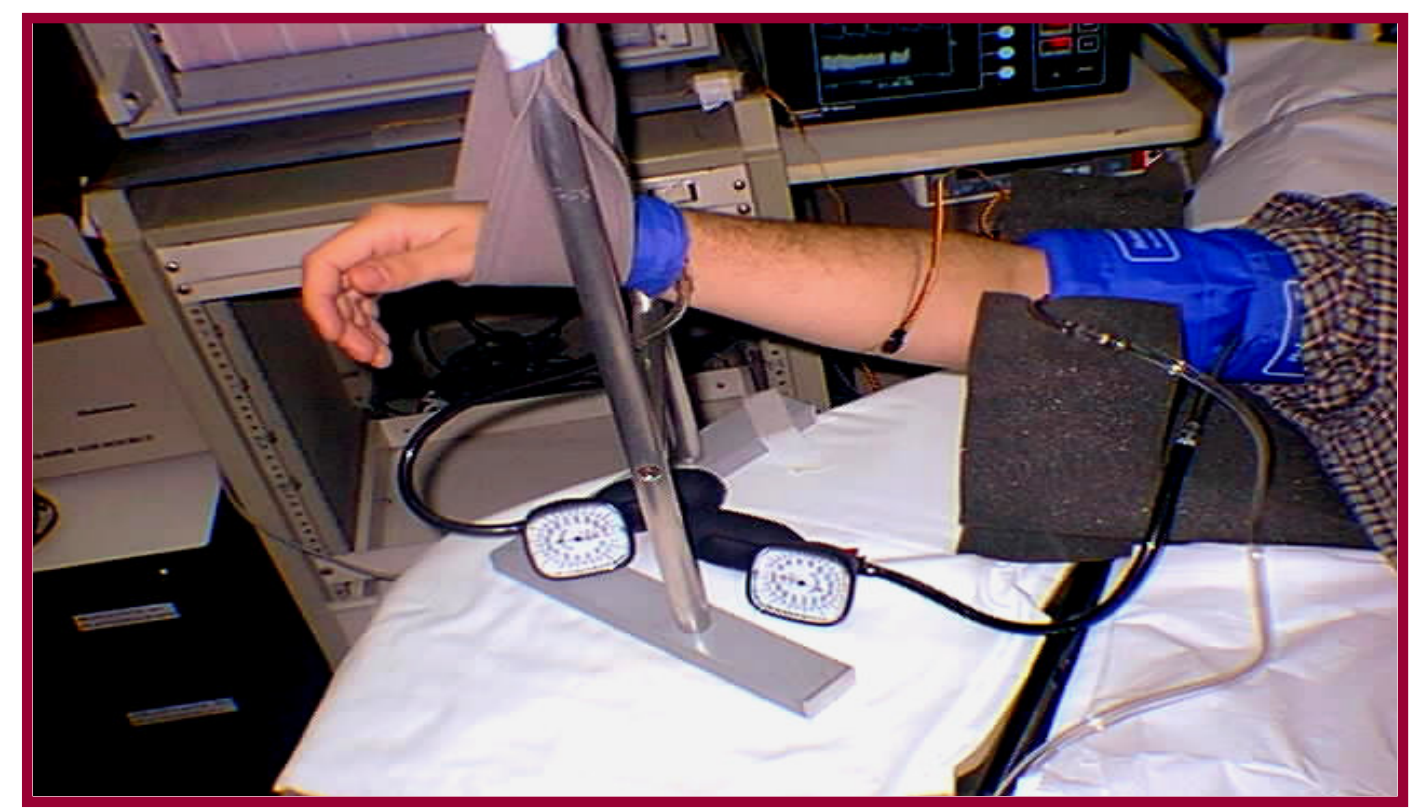

\subsubsection{Questionário sobre a qualidade de vida em pacientes com IC (anexo 3)}

O Minessota Living With Heart Failure Questionnaire (LihFE) foi desenvolvido em 1984 para identificar o impacto da terapêutica medicamentosa e da IC na qualidade de vida. Para mensurar os efeitos dos sintomas na limitação funcional, estresse psicológico e impacto socioeconômico, o MLHF consta de 21 questões e pede para que o paciente identifique em uma escala de zero (não) a cinco (demais) o quanto a insuficiência cardíaca os impede de viverem como eles 
gostariam. O domínio físico foi calculado como a soma de oito questões $(2,3,4,5$, $6,7,12$ e 13) e estão relacionadas à dispnéia e fadiga; o escore domínio emocional é composto de cinco questões $(17,18,19,20$ e 21). As demais questões (um, oito, nove, 10,11, 14,15 e 16) somadas ao domínio físico e emocional, formam o escore total ${ }^{93}$.

Deve-se sempre esclarecer ao paciente que ele deverá considerar o último mês para responder aos questionamentos.

\subsubsection{Treinamento da musculatura inspiratória}

Para o protocolo de TMI, foi utilizado o aparelho Threshold Inspiratório IMT (Globalmed, Porto Alegre - RS), que consiste em sistema fluxo independente que não requer uma pressão predeterminada para iniciar a inspiração e expiração. Quando a inspiração ou expiração for iniciada, a pressão necessária para manter a válvula aberta é constante e independente do fluxo. As pressões podem ser ajustadas de 7 á $41 \mathrm{cmH}_{2} \mathrm{O}$.

Os pacientes incluídos no Grupo TMI foram orientados para utilizar o threshold inspiratório no seu domicílio: eles deveriam permanecer sentados, com os cotovelos apoiados e com clipe nasal e realizar inspirações e expirações contra uma carga de $30 \%$ da $\mathrm{Pi}_{\text {máx }}$ de repouso, para evitar acúmulo de saliva, eles poderiam retirar o aparelho da boca pra deglutir a saliva quando houvesse necessidade. O exercício deveria ser realizado durante doze semanas, sete dias 
da semana durante 30 minutos, subdivididos em três séries de 10 minutos cada. Mensalmente os pacientes retornavam ao Laboratório de Investigação Clínica em Hipertensão no Instituto do Coração para a reavaliação da $\mathrm{Pi}_{\text {máx }}$ e reajuste na nova carga, caso o paciente não conseguisse realizar o exercício respiratório, era orientado a manter a mesma carga de início ${ }^{12,95}$.

Em casos de intolerância ao exercício ou impossibilidade de retornos mensais o pacientes seria retirado do protocolo de pesquisa.

\subsection{ANÁLISE ESTATÍSTICA}

Para a presente análise utilizou-se o programa de análise estatística Statistic (WinStat, Microsoft).

As variáveis classificatórias foram apresentadas em tabelas contendo freqüências absolutas (n) e relativas (\%). As variáveis quantitativas foram apresentadas descritivamente em tabelas contendo média e erro padrão e comparadas com teste t- Student, após ter sido confirmada distribuição normal com o teste de normalidade de Kolmorogov.

O teste de análise de variância (ANOVA) de medidas repetidas, de uma ou duas vias, seguido de testes complementares de Student Newman Keuls foram devidamente aplicados para análise de dados. Valores de $p<0,05$ foram considerados significativos. 


\section{RESULTADOS}

\subsection{Casuística}

Foram avaliados 60 pacientes provenientes do Ambulatório de Miocardiopatia e Hipertensão do InCor. Trinta e um pacientes preencheram os critérios de inclusão e realizaram a avaliação inicial, e destes, 29 pacientes foram alocados de forma seqüencial no Grupo Controle ( $n=12)$ e Grupo TMI (15). Dois pacientes não completaram o estudo: um apresentou fibrilação atrial durante o estudo e outro desistiu de participar do protocolo. Desta forma, 27 pacientes completaram o estudo.

A tabela 1 apresenta as características clínicas do grupo Controle e grupo TMI. Não houve diferenças significativas com relação à distribuição do sexo, idade, IMC, $\mathrm{Pi}_{\text {máx }}$ e FE entre as médias dos grupos quando comparadas pelo teste $t$ de Studen

Tabela 1. Características clínicas dos pacientes.

\begin{tabular}{lccc}
\hline \hline & $\begin{array}{c}\text { Grupo Controle } \\
(\mathrm{N}=12)\end{array}$ & $\begin{array}{c}\text { Grupo TMI } \\
(\mathrm{N}=15)\end{array}$ & $\mathrm{p}$ \\
& $5 / 7$ & $9 / 6$ & \\
\hline Sexo, M/F & $53,3 \pm 2,3$ & $54,3 \pm 2$ & $>0,05$ \\
Idade, anos & $28,8 \pm 1,6$ & $27,4 \pm 0,9$ & $>0,05$ \\
Índice de Massa Corporal & $56,2 \pm 2,1$ & $56,1 \pm 2,3$ & $>0,05$ \\
Pi & & & \\
Fração de Ejeção, \% & $37,6 \pm 1,6$ & $33,6 \pm 2,3$ & $>0,05$ \\
\hline \hline
\end{tabular}

Os valores são expressos em Média e Erro Padrão (EP). 
Na tabela 2 encontram-se a relação de medicações (\%) utilizadas pelos pacientes de ambos os grupos durante o protocolo.

Pode-se notar que não houve diferença significativa entre as medicações utilizadas em ambos os grupos. Todos os pacientes estavam estáveis, utilizando inibidores do sistema renina angiotensina (IECA/ BRA), Beta Bloqueador e outras medicações, de acordo com indicação.

Tabela 2. Relação de medicações (\%) utilizadas pelos pacientes de ambos os grupos durante o protocolo

\section{Grupo Controle (n-12) Grupo TMI $(n=15) \quad p$}

Medicações ,\% (n)

Digoxina

Diuréticos

IECA / BRA

Beta Bloqueador
50 (6)

83 (10)

$100(12)$

$100(12)$
40 (6)

86,6 (13)

$100(15)$

$100(15)$
$>0,05$

$>0,05$

$>0,05$

$>0,05$

Valores em porcentagem. Não houve diferença significativa, quando comparadas através do Test $t$ de Student.

Os pacientes alocados no Grupo TMI, durante o protocolo foram orientados a preencherem um protocolo de adesão ao treinamento, dos quinze pacientes que finalizaram o protocolo, 95\% realizaram o exercício sem interrupções e realizaram as reavaliações mensalmente. Somente, 5\% dos pacientes referiram um período de uma semana de interrupção no TMI, retornando ao protocolo após primeira reavaliação. 
Os motivos da interrupção do exercício foram associados a esquecimento e falta de tempo para a realização dos exercícios. Nenhum paciente referiu dor torácica, dispnéia e tontura durante as sessões.

\subsection{Efeito do TMI na força e resistência dos músculos inspiratórios}

No início do protocolo, os valores basais da $\mathrm{Pi}_{\operatorname{máx}}$ nos grupos Controle e grupo TMI eram semelhantes.

Após 12 semanas observou-se um aumento significativo na $\mathrm{Pi}_{\text {máx }}$ no grupo TMI (basal 59,2 $\mathrm{cmH}_{2} \mathrm{O} \pm 4,9$ vs pós $87,5 \mathrm{cmH}_{2} \mathrm{O} \pm 6,5$ ), enquanto que no grupo Controle os valores permaneceram inalterados (basal 62,3 $\mathrm{cmH}_{2} \mathrm{O} \pm 5,3$ vs pós $67,8 \pm 5,8 \mathrm{cmH}_{2} \mathrm{O}$ ). $\mathrm{O}$ aumento observado na $\mathrm{Pi}_{\text {máx }}$ no grupo TMI foi de 47\% em relação ao seu basal, como podemos observar na Figura 7.

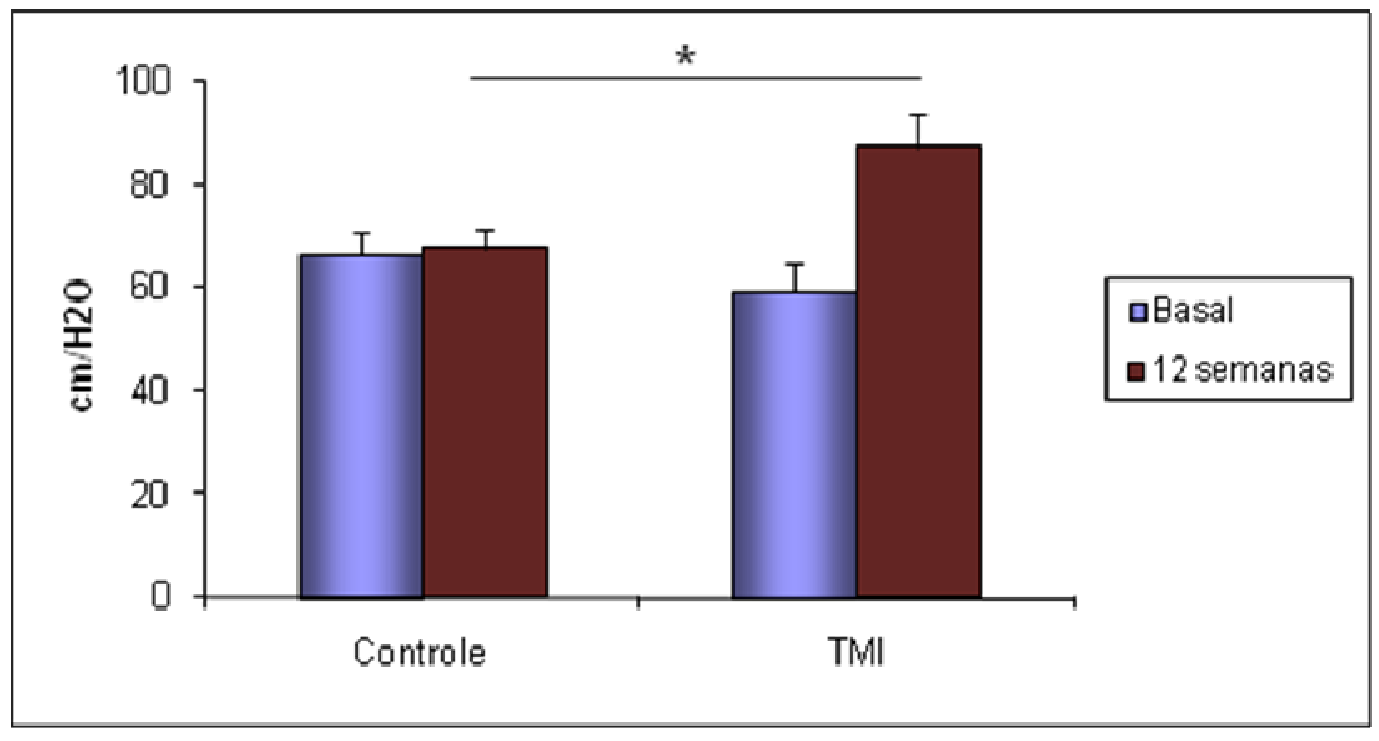

Figura 7: Valores da $\mathrm{Pi}_{\text {máx }}$ (média e EP) nos grupos Controle $(n=12)$ e TMI $(n=15)$ no período basal e após 12 semanas e grupo TMI $(n=15)$ no período basal e após 12 semanas. ${ }^{*} p<0,05$ Grupos Controle e TMI basal vs 12 semanas. 
Os pacientes incluídos no protocolo realizaram concomitantemente a avaliação da $P e_{\operatorname{Max}}$ no início do protocolo. Observou-se uma forte correlação significativa entre fraqueza da musculatura inspiratória no Grupo Controle $\left(R_{2}=0,54\right)$ e Grupo TMI $\left(R_{2}=0,63\right)$, como se pode observar nas Figuras 8 e 9.

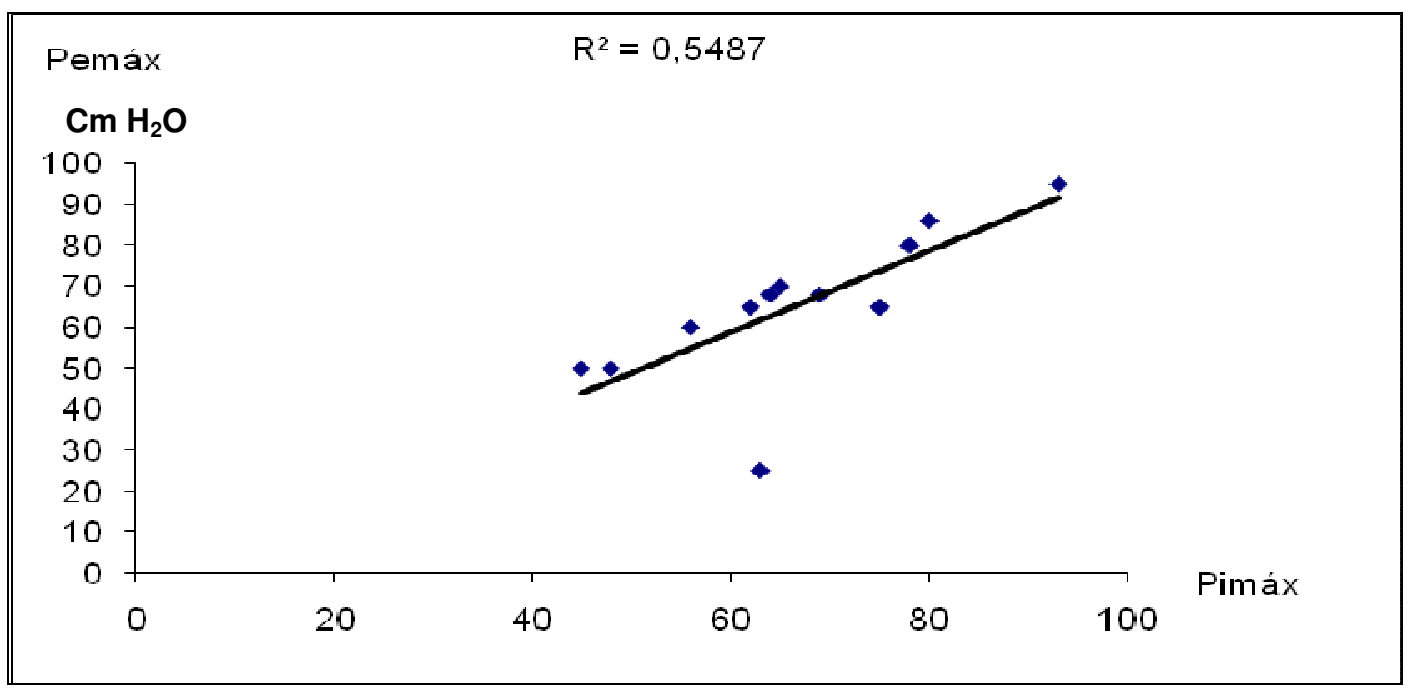

Figura 8. Correlação de Pearson entre $\mathrm{Pi}_{\text {máx }}$ e $\mathrm{Pe}_{\text {máx }}$ para pacientes incluídos no Grupo Controle (N=12). ${ }^{*} \mathrm{p}<0,05$ Grupo Controle $\mathrm{Pi}_{\text {máx }}$ vs $\mathrm{Pe}_{\text {máx. }}$

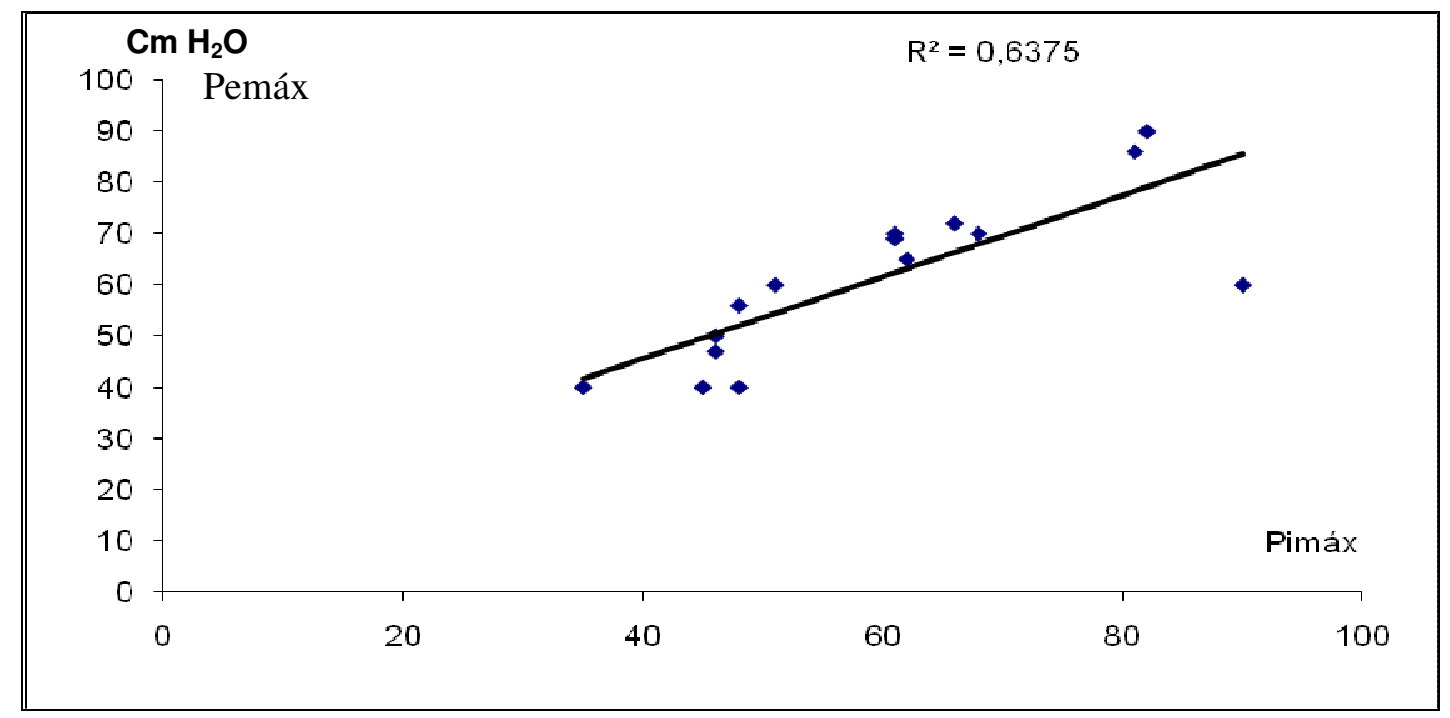

Figura 9. Correlação de Pearson entre $\mathrm{Pi}_{\operatorname{máx}}$ e $\mathrm{Pe}_{\text {máx }}$ dos pacientes incluídos no Grupo TMI (N=15). " $\mathrm{p}<0,05$ Grupo TMI Pi máx vs $P e_{\text {máx. }}$ 
Deve-se ressaltar que a carga do Threshold inspiratório foi ajustada mensalmente de acordo com a força máxima inspiratória mensurada através da Pimáx. Na figura 10 observa-se o aumento progressivo da força muscular inspiratória nas reavaliações mensais.

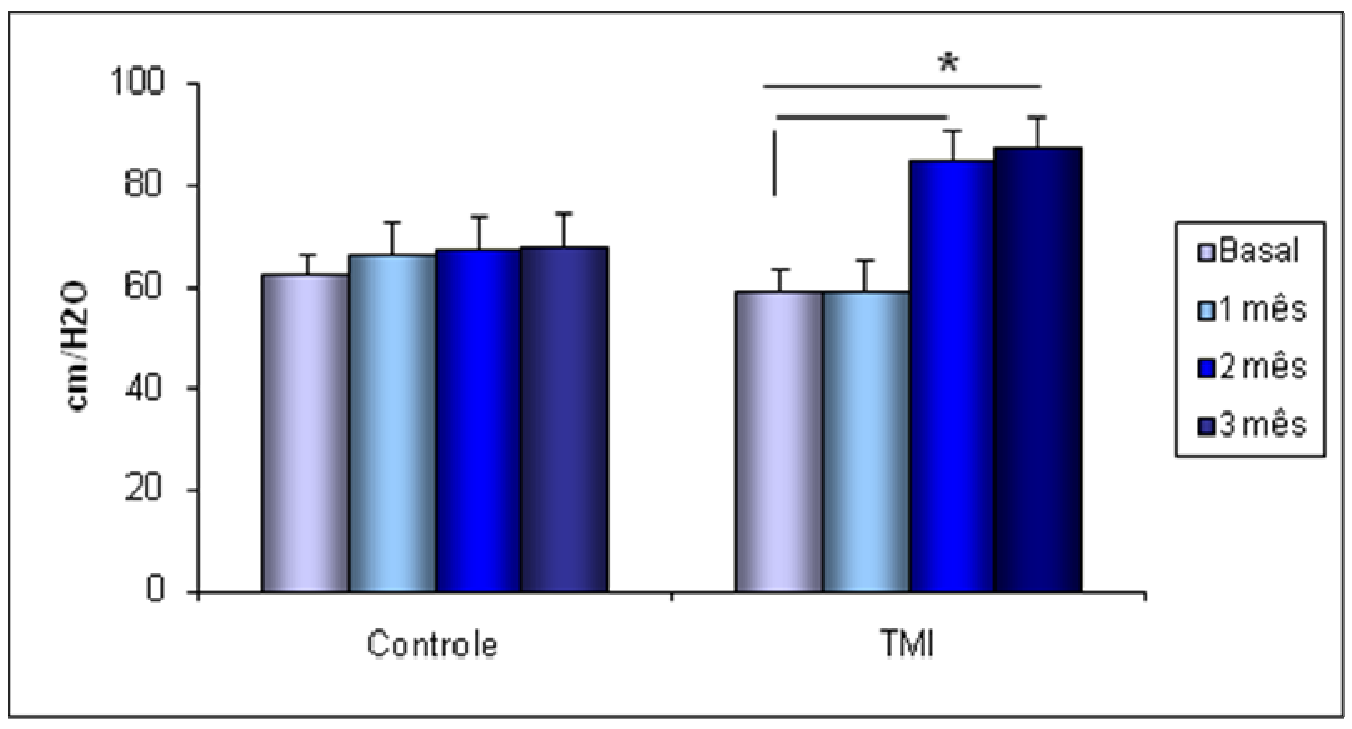

Figura 10. Reavaliação mensal realizadas pelos grupos Controle $(n=12)$ e TMI $(\mathrm{N}=15)$. Os valores estão expressos em média e erro padrão. * $\mathrm{p}<0,05$ Grupo TMI

\subsection{Efeito do TMI sobre as variáveis hemodinâmicas}

$\mathrm{Na}$ condição basal não houve diferença significativa quanto aos parâmetros hemodinâmicos: FC, PAS, PAD, VS, DC. A RVP foi maior no grupo submetido ao TMI, apesar de não ter atingido diferença estatística (Tabela 3).

Após 12 semanas as variáveis hemodinâmicas: FC, PAS, PAD, VS, DC e RVP não apresentaram diferença estatística no grupo Controle. No grupo 
TMI, as variáveis RVP, PAS e PAD diminuíram, apesar de não apresentar diferença significativa. Tabela 3.

Tabela 3. Variáveis hemodinâmicas no período basal e após 12 semanas nos grupo Controle e grupo TMI.

\begin{tabular}{llccc}
\hline \hline & \multicolumn{2}{c}{ Controle } & Basal \\
& $(\mathrm{n}=12)$ & $\begin{array}{c}12 \text { sem } \\
(\mathrm{n}=12)\end{array}$ & $\begin{array}{c}\text { Basal } \\
(\mathrm{n}=15)\end{array}$ & $\begin{array}{c}12 \mathrm{sem} \\
(\mathrm{n}=15)\end{array}$ \\
\hline $\mathrm{FC}(\mathrm{bpm} / \mathrm{min})$ & $70,3 \pm 3,3$ & $68,5 \pm 3,4$ & $65,6 \pm 3$ & $62,3 \pm 2,5$ \\
PAS (mmHg) & $134,0 \pm 5$ & $132,7 \pm 3,5$ & $133,9 \pm 5$ & $124,9 \pm 5$ \\
PAD (mmHg) & $78 \pm 2,5$ & $75,5 \pm 1,9$ & $77,8 \pm 3,3$ & $70,9 \pm 3,6$ \\
VS (ml) & $71 \pm 3$ & $69,4 \pm 4,4$ & $74,8 \pm 6,3$ & $74,0 \pm 5,3$ \\
RVP(unit) & $1,26 \pm 0,1$ & $1,32 \pm 0,1$ & $1,20 \pm 0,1$ & $1,10 \pm 0,1$ \\
DC (l/min) & $4,9 \pm 0,2$ & $4,6 \pm 0,3$ & $4,6 \pm 0,4$ & $5,2 \pm 0,3$ \\
\end{tabular}

Os valores estão expressos em média e erro padrão.

\subsection{Efeito do TMI na Capacidade Funcional Cardiorrespiratória}

\section{Efeito do TMI no consumo de oxigênio $\left(\mathrm{VO}_{2}\right)$}

$\mathrm{Na}$ avaliação basal, o grupo Controle e grupo TMI apresentaram valores semelhantes de $\mathrm{VO}_{2}$ pico (Figura 16). Após 12 semanas o grupo TMI apresentou aumento significativo no $\mathrm{VO}_{2}$ pico $(14,4 \mathrm{ml} / \mathrm{kg} / \mathrm{min} \pm 1,03$ vs 18,9 $\mathrm{ml} / \mathrm{kg} / \mathrm{min} \pm 1,16$ ), correspondendo a um aumento de $13,52 \%$. O grupo Controle não apresentou variação significativa $(16,2 \mathrm{ml} / \mathrm{kg} / \mathrm{min} \pm 0,9 \mathrm{vs} 16,3 \mathrm{ml} / \mathrm{kg} / \mathrm{min} \pm$ 0,9). Figura 11 


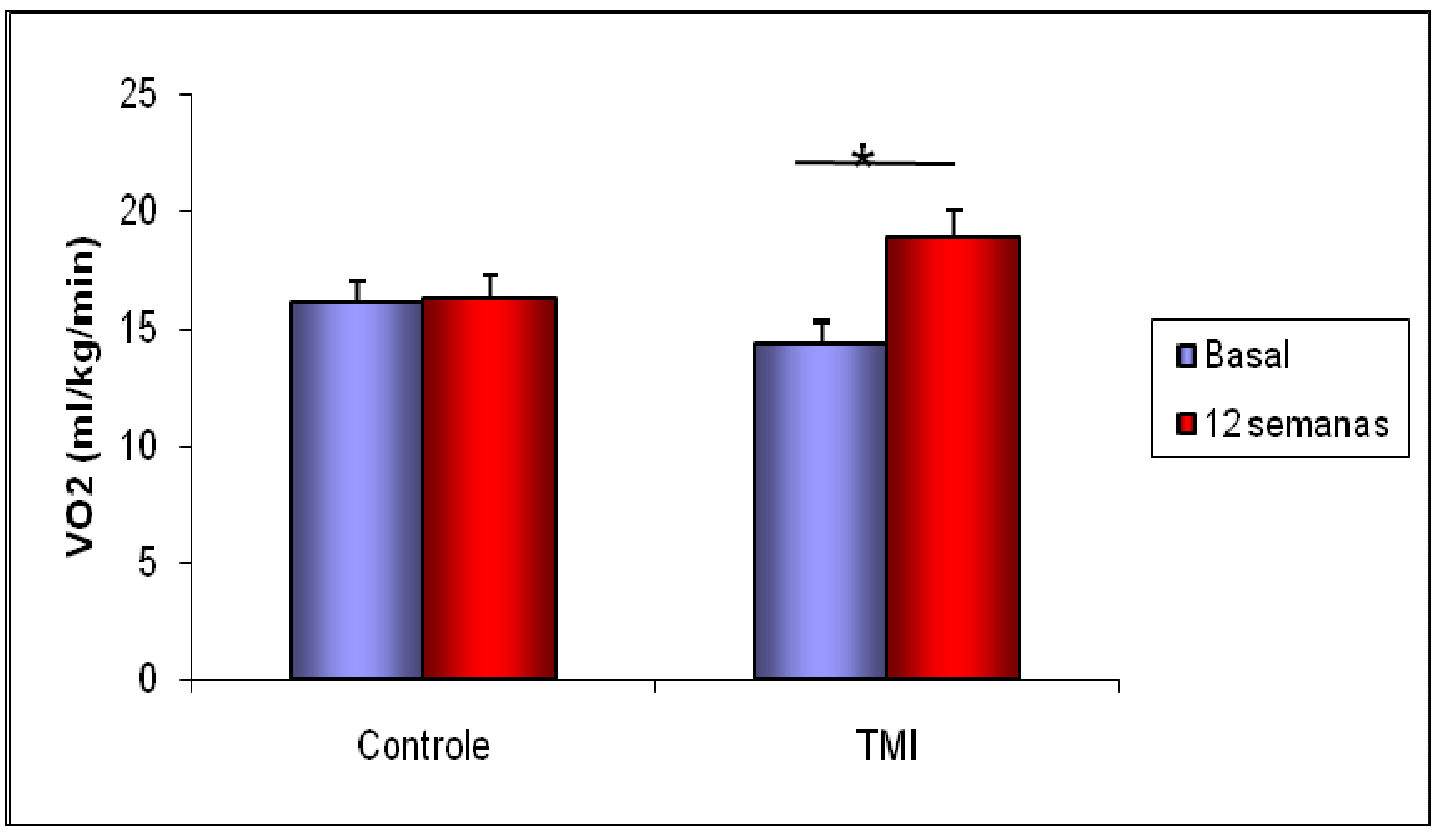

Figura 11. Valores do $\mathrm{VO}_{2}$ pico nos grupo Controle $(\mathrm{n}=12)$ e TMI $(\mathrm{n}=15)$ no período basal e após 12 semanas. Os valores estão expressos em média e erro padrão.

* $\mathrm{p}<0,05$ - Grupo TMI no momento basal vs. 12 semanas.

Efeito do TMI no equivalente ventilatório de gás carbônico $\left(\mathrm{VE} / \mathrm{VCO}_{2}\right)$

$\mathrm{Na}$ avaliação basal, ambos os grupos apresentaram valores semelhantes de $\mathrm{VE} / \mathrm{VCO}_{2}$ pico. Após 12 semanas o grupo TMI apresentou diminuição significativa no $\mathrm{VE} / \mathrm{VCO}_{2}$ pico $(35,8 \mathrm{ml} / \mathrm{kg} / \mathrm{min} \pm 0,4$ vs 32,5 $\mathrm{ml} / \mathrm{kg} / \mathrm{min} \pm 0,8)$ não ocorrendo o mesmo no grupo Controle $(36,1 \mathrm{ml} / \mathrm{kg} / \mathrm{min} \pm$ $0,48 \mathrm{vs} 36,1 \mathrm{ml} / \mathrm{kg} / \mathrm{min} \pm 0,43)$. Figura 12 


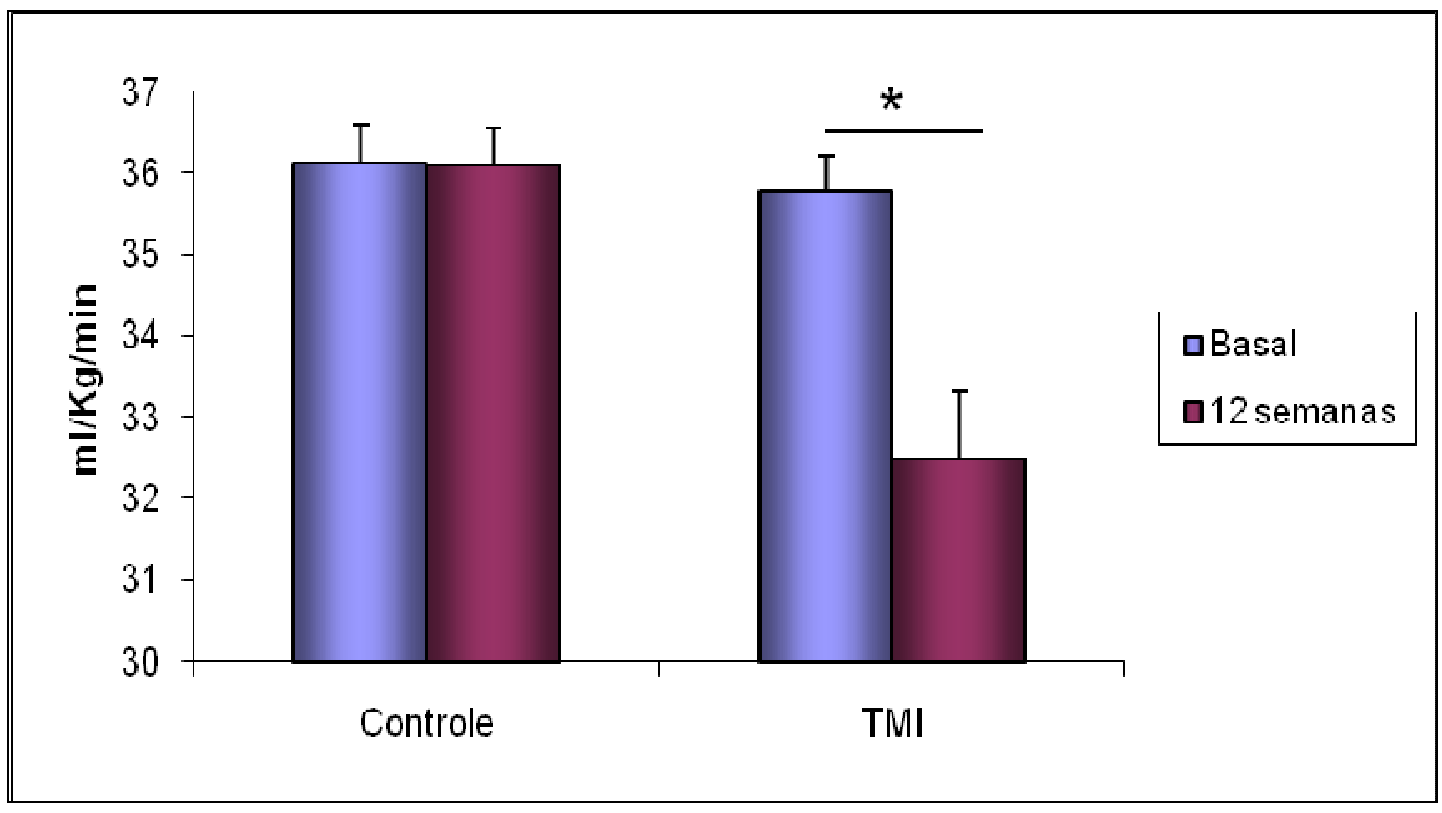

Figura 12. Valores do $\mathrm{VE} / \mathrm{VCO}_{2}$ pico nos grupo Controle $(\mathrm{n}=12)$ e TMI $(n=15)$ no período basal e após 12 semanas. Os valores estão expressos em média e erro padrão.

* $p<0,05-$ Grupo TMI no momento basal vs. 12 semanas.

\section{Duração do teste máximo cardiorrespiratório}

$\mathrm{Na}$ avaliação basal os grupos Controle e TMI apresentavam valores semelhantes de tempo de exercício (Figura 17). Após 12 semanas, o grupo TMI não apresentou aumento significativo na duração de tempo de exercício ( $8,6 \pm 0,55$ vs $10,5 \pm 0,60$ minutos) em relação ao grupo Controle ( $9,1 \pm 0,96$ vs $8,0 \pm 1,2$ minutos). Figura 13 


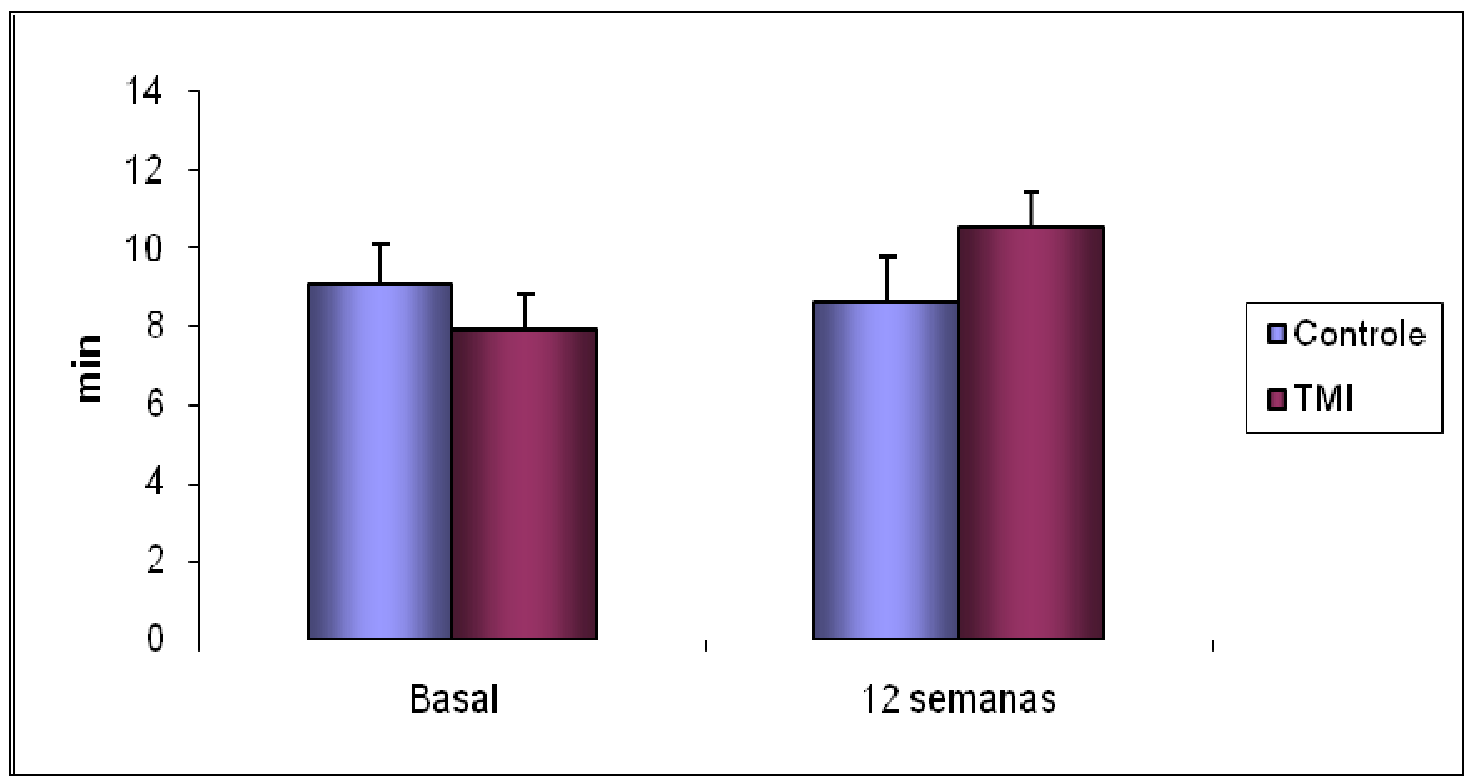

Figura 13. Valores da duração do exercício ergoespirométrico nos grupos Controle $(n=12)$ e TMI $(n=15)$ no período basal e após 12 semanas.

Os valores estão expressos em média e erro padrão.

\subsection{Efeito do TMI na variabilidade da FC e PA.}

\section{Variabilidade da freqüência cardíaca}

$\mathrm{Na}$ avaliação basal os grupos Controle e TMI apresentavam valores semelhantes das variáveis VLF, LF, HF, LF\%, HF\% e LF/HF. Após 12 semanas, o grupo TMI apresentou diminuição do componente LF no seu valor absoluto $\left(607,18 \mathrm{mms}^{2} \pm 153,9\right.$ vs $\left.263,51 \mathrm{mms}^{2} \pm 53,6\right)$, e no seu valor normalizado $(6,18 \pm 1,7 \mathrm{nu}$ vs $5,04 \mathrm{nu} \pm 1,1)$. Observamos ainda, um aumento do componente HF no seu valor normalizado no Grupo TMI (48,41 \pm 4,4 nu vs 56,7 nu $\pm 4,4$ ), não ocorrendo o mesmo no grupo Controle. Tabela 4. As outras variáveis analisadas não apresentaram alteração estatística significativa nos grupos Controle e TMI. 
Tabela 4. Valores dos componentes da variabilidade da FC, nos grupos Controle e TMI pré e após 12 semanas.

\begin{tabular}{llccc}
\hline & \multicolumn{2}{c}{ Controle } & \multicolumn{2}{c}{ TMI } \\
\hline & $\begin{array}{l}\text { Basal } \\
(\mathrm{n}=11)\end{array}$ & $\begin{array}{c}12 \mathrm{sem} \\
(\mathrm{n}=11)\end{array}$ & $\begin{array}{c}\text { Basal } \\
(\mathrm{n}=14)\end{array}$ & $\begin{array}{c}12 \text { sem } \\
(\mathrm{n}=14)\end{array}$ \\
\hline $\mathrm{PWT}\left(\mathrm{mms}^{2}\right)$ & $1469,6 \pm 574,8$ & $974,2 \pm 375,2$ & $1635,8 \pm 252,7$ & $946,3 \pm 89,5$ \\
$\mathrm{LF}\left(\mathrm{mms}^{2}\right)$ & $393,85 \pm 118,0$ & $287,1 \pm 38,4$ & $607,1 \pm 153,9$ & $263,5 \pm 53,6^{*}$ \\
$\mathrm{HF}\left(\mathrm{mms}^{2}\right)$ & $379,82 \pm 68,2$ & $159,1 \pm 33,5$ & $461,62 \pm 104,6$ & $313,3 \pm 58,8$ \\
$\mathrm{LF}(\mathrm{NU})$ & $44,2 \pm 5,19$ & $37,0 \pm 6,6$ & $51,6 \pm 4,4$ & $43,2 \pm 4,4^{*}$ \\
$\mathrm{HF}(\mathrm{NU})$ & $55,7 \pm 5,19$ & $63,01 \pm 6,6$ & $48,41 \pm 4,4$ & $56,7 \pm 4,4^{*}$ \\
$\mathrm{LF} / \mathrm{HF}$ & $0,94 \pm 0,16$ & $0,84 \pm 0,2$ & $1,29 \pm 0,2$ & $0,92 \pm 0,2$ \\
\hline
\end{tabular}

Os valores estão expressos em média e erro padrão.

${ }^{*} p<0,05-$ Grupo TMI no momento basal vs. 12 semanas.

\section{Variabilidade da Pressão Arterial}

$\mathrm{Na}$ avaliação basal os grupos Controle e TMI apresentaram valores semelhantes nas variáveis analisadas, nos componentes da variabilidade da PA e na variância da pressão sistólica (VARPAS) em valores normalizados dos seus componentes. Após 12 semanas os grupos Controle e TMI não apresentaram diferença estatística nas variáveis acima citadas, como demonstradas na Tabela 5. 
Tabela 5. Valores da variabilidade da PA, nos grupos Controle e TMI pré e após 12 semanas.

Controle

Basal

$(n=11)$

LF (NU)

$\mathrm{HF}(\mathrm{NU})$

VARPAS $\left(\mathrm{mms}^{2}\right) 6,29 \pm 0,8$
$5,70 \pm 1,9$

$4,86 \pm 1,4$
12 sem

$(\mathrm{n}=11)$

$5,02 \pm 1,0$

$4,13 \pm 1,7$

$4,92 \pm 4,3$
TMI

$\begin{array}{cc}\text { Basal } & 12 \text { sem } \\ (n=14) & (n=14)\end{array}$

$(n=14)$

$\begin{array}{rr}6,18 \pm 1,7 & 5,04 \pm 1,1 \\ 5,3 \pm 1,0 & 6,45 \pm 1,8 \\ 4,98 \pm 4,9 & 5,10 \pm 0,4\end{array}$

Os valores estão expressos em média e erro padrão

\section{Atividade Simpática Periférica (ANSP)}

Durante o período basal não foi observada diferença estatística significativa na ASP entre o grupo Controle (34,0 disparos por minuto) e grupo TMI (37,1 disparos/ minuto). Após 12 semanas, observou-se uma diminuição significativa na ASP no grupo TMI (37,1 \pm 3 vs 29,5 $\pm 2,3$ disparos/ minuto), o que representa $20 \%$ de diminuição da atividade simpática periférica não ocorrendo o mesmo no grupo Controle que permaneceu com o mesmo nível de atividade simpática (34,0 $\pm 3,2$ vs após 33,7 $\pm 2,7$ disparos/ minuto). Figura 14 


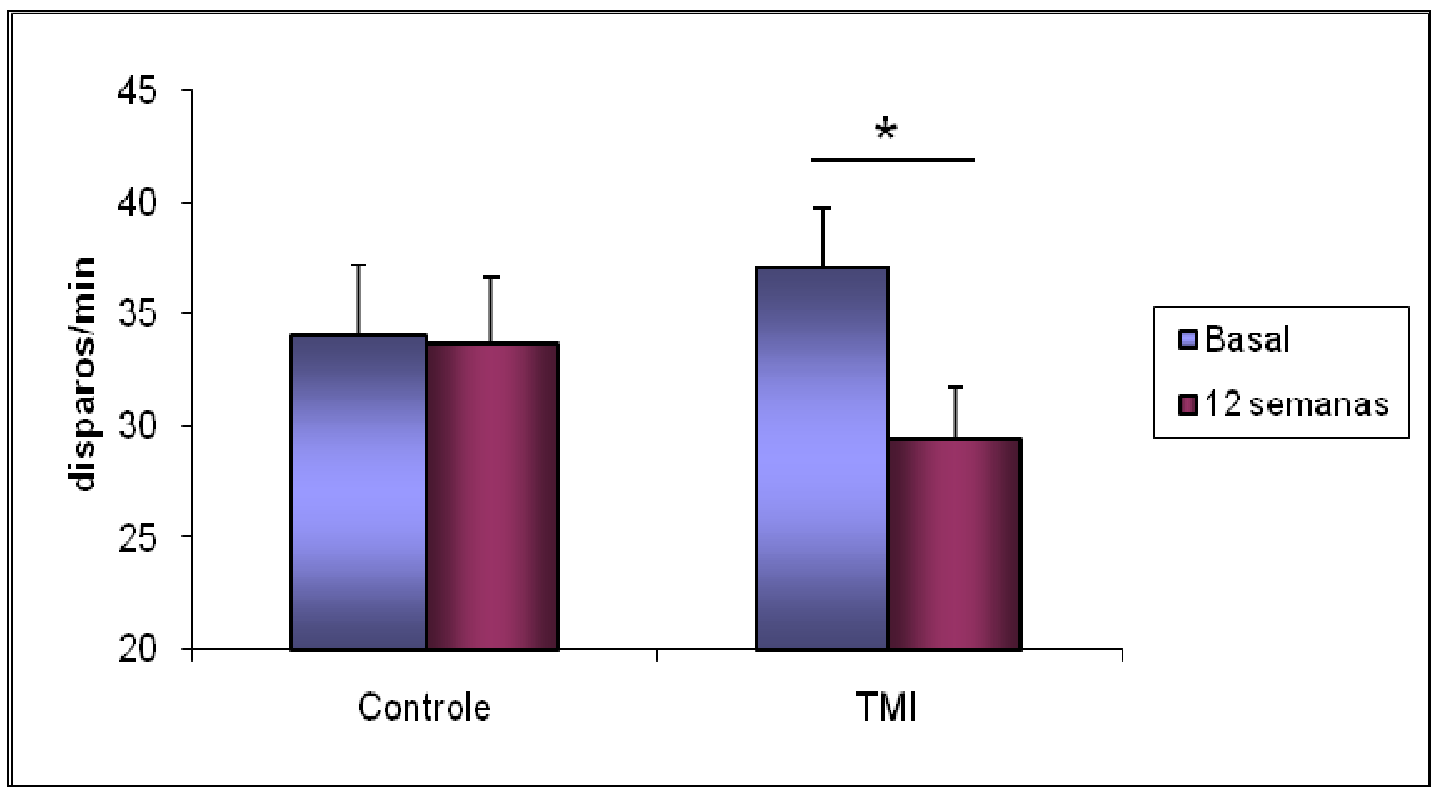

Figura 14. Valores da ANSP no período basal e após 12 semanas nos grupos Controle $(n=12)$ e TMI $(n=14)$. Os valores estão expressos em média e erro padrão.

* $\mathrm{p}<0,05$ - Grupo TMI no momento basal vs. 12 semanas.

\subsection{Efeito do TMI sobre o fluxo de sangue para o antebraço (FSA)}

Quando avaliado através da técnica de pletismografia por oclusão venosa, observamos que não houve diferença estatística entre os momentos basal e após 12 semanas nos valores de FSA em repouso no grupo Controle (pré $1,85 \mathrm{ml} / 100 \mathrm{ml}$ tecido/min $\pm 0,2$ vs pós $1,97 \mathrm{ml} / 100 \mathrm{ml}$ tecido/min $\pm 0,3$ ) e grupo TMl (pré 2,4 $\pm \mathrm{ml} / 100 \mathrm{ml}$ tecido/min $\pm 0,2 \mathrm{vs}$ pós $2,32 \mathrm{ml} / 100 \mathrm{ml}$ tecido/min $\pm 0,5)$. Figura 15 . 


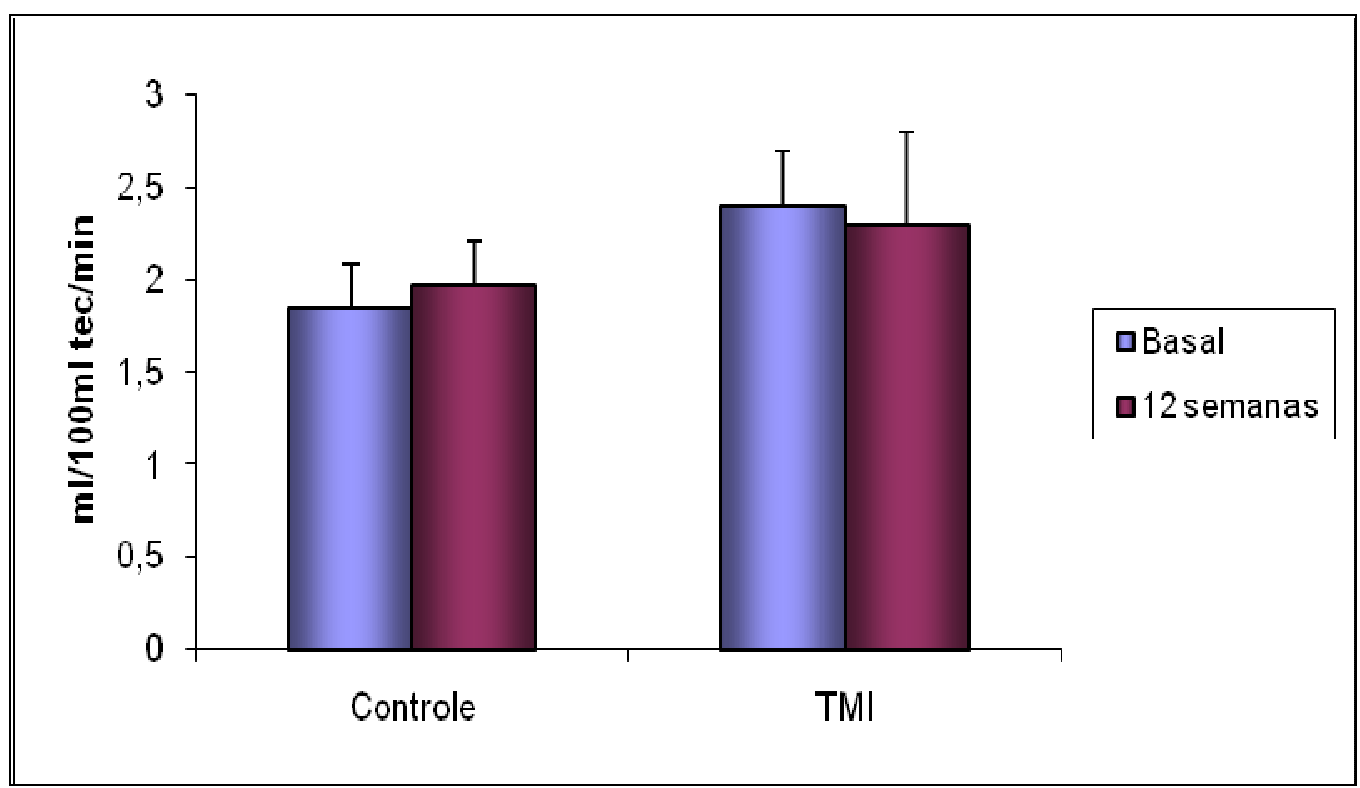

Figura 15. Valores do fluxo de sangue para o antebraço em repouso no período basal e após 12 semanas nos grupos Controle $(n=12)$ e TMI $(n=10)$.

Os valores estão expressos em média e erro padrão.

Observamos que não houve diferença estatística e significativa do aumento de fluxo entre os momentos basal e após 12 semanas nos valores de no grupo Controle (pré $3,4 \mathrm{ml} / 100 \mathrm{ml}$ tecido/min $\pm 0,3$ vs pós $3,1 \mathrm{ml} / 100 \mathrm{ml}$ tecido/min $\pm 0,3$ ) e grupo TMI (pré 3,0 $\pm \mathrm{ml} / 100 \mathrm{ml}$ tecido/min $\pm 0,3$ vs pós 2,9 $\mathrm{ml} / 100 \mathrm{ml}$ tecido/min). Figura 16 


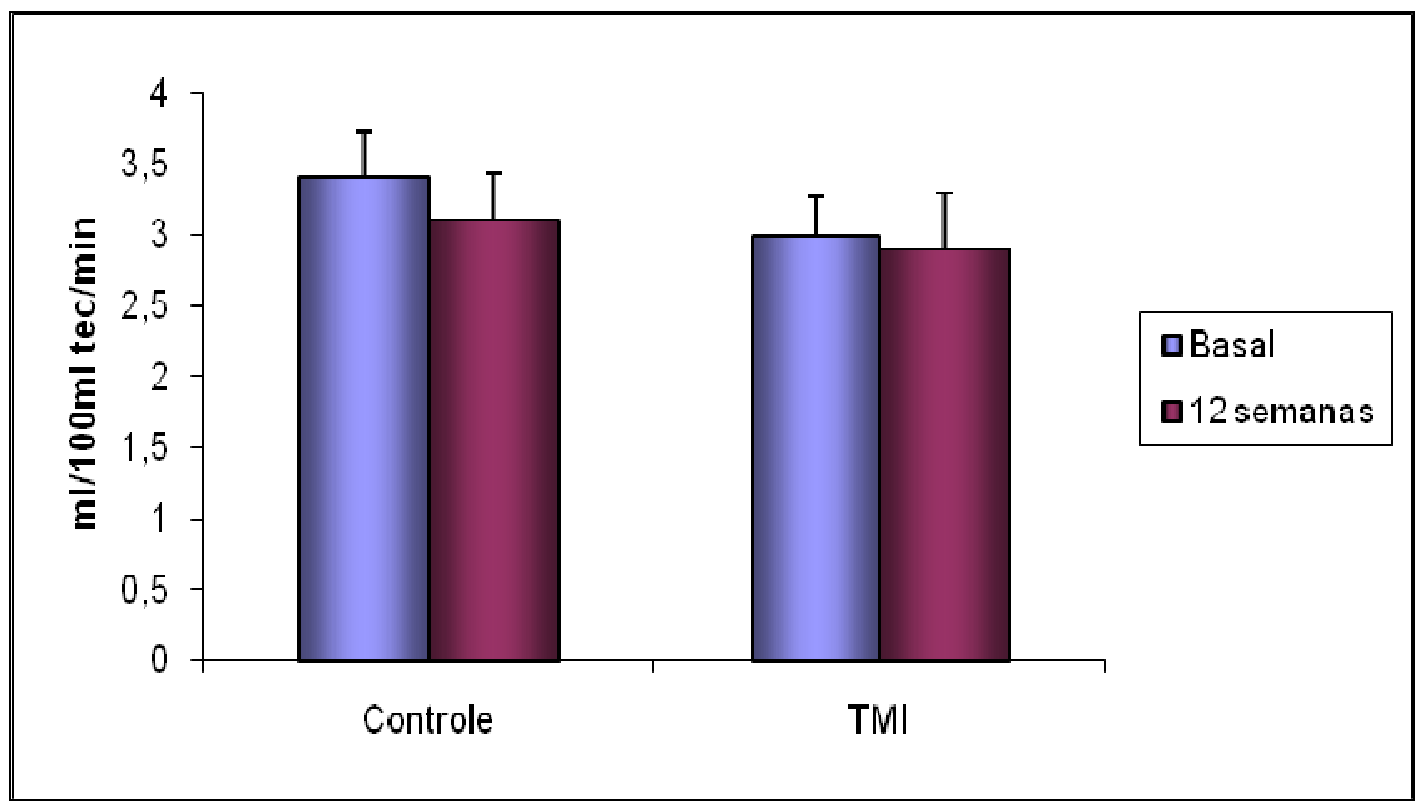

Figura 16. Valores do fluxo de sangue para o antebraço no exercício isométrico no momento basal e após 12 semanas nos grupos Controle $(n=12)$ e TMI $(n=10)$. Os valores estão expressos em média e erro padrão.

\subsection{Efeito do TMI sobre a qualidade de vida dos pacientes com IC}

No período basal o grupo Controle e grupo TMI não apresentaram diferença significativa, quando se avaliou a qualidade de vida (Questionário Minessota). Após 12 semanas, houve uma diminuição significativa na pontuação nos domínio físico e geral no grupo TMI. Tabela 6. 
Tabela 6. Questionário de Minessota no período basal e após 12 semanas nos grupos e TMI.

\begin{tabular}{lcccc}
\hline \hline & \multicolumn{2}{c}{ Controle } & & TMI \\
\cline { 2 - 5 } & $\begin{array}{c}\text { Basal } \\
(\mathrm{n}=12)\end{array}$ & $\begin{array}{c}12 \mathrm{sem} . \\
(\mathrm{n}=15)\end{array}$ & $\begin{array}{c}\text { Basal } \\
(\mathrm{n}=12)\end{array}$ & $\begin{array}{r}12 \mathrm{sem} . \\
(\mathrm{n}=15)\end{array}$ \\
\hline \hline Geral & $30,8 \pm 6,1$ & $32,7 \pm 5,6$ & $23,6 \pm 3,8$ & $9,2 \pm 2,4$ \\
Físico & $23,7 \pm 5,5$ & $25,2 \pm 5,2$ & $20,2 \pm 3,5$ & $7,6 \pm 2,2$ \\
\hline \hline
\end{tabular}

Os valores estão expressos em média e erro padrão.

* $\mathrm{p}<0,05$ - Grupo TMI no momento basal vs. 12 semanas. 


\section{DISCUSSÃO}

O principal resultado do nosso estudo foi a demonstração de que o TMI, além de aumentar a força e resistência dos músculos inspiratórios e melhorar a capacidade funcional cardiorrespiratória e a qualidade de vida, diminuiu significativamente a atividade nervosa simpática periférica e cardíaca de pacientes com IC hipertensiva. Podemos inferir que a redução da atividade simpática pode ser um dos mecanismos que colaboram para os efeitos benéficos que o TMI promove na população estudada.

A discussão será feita na forma de tópicos, seguindo a seqüência de apresentação dos objetivos.

\section{Efeito do TMI na força e resistência dos músculos respiratórios}

Seguindo o critério de inclusão, na nossa população os valores de repouso da $\mathrm{Pi}_{\text {máx }}$ apresentaram $26 \%$ de diminuição em média com relação ao valor predito. Ainda que o foco do nosso estudo tenha sido a $\mathrm{Pi}_{\text {máx }}$, avaliamos também a correlação entre esta variável e a $\mathrm{Pe}_{\operatorname{máx}}$. A expiração é passiva em repouso, mas durante o exercício, os músculos abdominais são recrutados para auxiliar a ventilação. Em pacientes com IC, a fraqueza da musculatura expiratória poderia também contribuir para diminuição da tolerância ao exercício ${ }^{96}$. $\mathrm{Na}$ avaliação inicial, observamos que ocorreu uma correlação

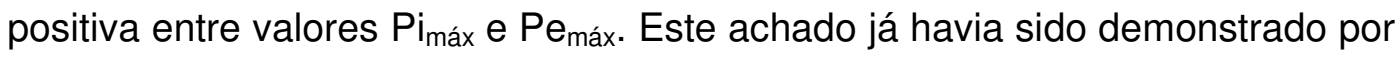
Hughes e cols ${ }^{97}$ que mostraram diminuição de $28 \%$ da $\mathrm{Pi}_{\text {máx }}$ e $20 \%$ da $\mathrm{Pe}_{\text {máx. }}$. Evan e cols ${ }^{98}$ acrescentaram a informação de que há correlação entre diminuição da $\mathrm{Pi}_{\text {máx }}$ e índices cardíacos, especificamente com valores menores 
de débito cardíaco, e sugeriram que a baixa perfusão muscular estaria envolvida na etiologia das doenças relacionadas aos músculos respiratórios.

De forma importante, a fraqueza da musculatura respiratória está associada à menor função pulmonar, especialmente na redução da capacidade vital forçada e pode estar associada com piora do risco cardiovascular ${ }^{99}$. De fato, Arora e cols. demonstraram que a desnutrição em pacientes com IC severa, resulta em uma atrofia muscular generalizada, diminuição de fibras musculares do diafragma e redução das pressões máximas de repouso pulmonar ${ }^{99}$. A fadiga diafragmática pode aumentar a vasoconstrição na musculatura torácica, o que pode ser atenuado com o TMI ${ }^{100}$. A fraqueza da musculatura inspiratória pode ser um importante mecanismo relacionado à sensação de dispnéia ${ }^{12}$.

A utilização do TMI como modalidade terapêutica foi adotada primariamente com o intuito de melhorar a força e resistência dos músculos respiratórios em pacientes com alterações respiratórias primárias (DPOC) ${ }^{12}$. Recentemente, esta modalidade de exercício vem sendo utilizada em pacientes com IC ${ }^{12,101 .}$

No nosso estudo, o TMI diário por doze semanas, com ajustes mensais da carga para manter $30 \%$ da $\mathrm{Pi}_{\text {máx }}$, levou a um incremento de $47 \%$ da $\mathrm{Pi}_{\text {máx. }}$ Esse aumento foi similar ao incremento observado em outros estudos, com protocolo semelhante de TMI, que em conjunto, apresentam um valor médio ao redor de $45 \%$ (variando de 20 a 70\%) na $\mathrm{Pi}_{\text {máx }}$ após um período e carga semelhantes de treinamento ${ }^{101,75,4}$. Nos estudos anteriores a população estudada era semelhante quanto à faixa etária e FEVE. Pudemos verificar que estudos em populações ou protocolos diferentes ao adotado têm impacto difícil 
de ser comparado, com relação a esta variável. Ainda, a adesão do paciente na realização do exercício é de fundamental importância. No nosso estudo, obtivemos uma a alta adesão ao exercício domiciliar (95\%).

Acredita-se que 0 incremento de força e resistência pode ser decorrência de diferentes mecanismos ${ }^{100}$. Alterações estruturais da musculatura associadas ao treinamento, incluindo hipertrofia da musculatura do diafragma ${ }^{101}$, e também a um maior redirecionamento de fluxo sanguíneo para esta região (melhorando parcialmente a baixa perfusão causada pelo débito cardíaco insuficiente), resultando em um equilíbrio na dinâmica respiratória ${ }^{67}$, 68, 102. Em estudos realizados em animais, verificou-se que, após treinamento físico aeróbio ocorreram adaptações celulares no diafragma, com aumento no número de mitocôndrias, fibras oxidativas (fibras de resistência) e hipertrofia da musculatura. Em modelos animais onde foi estimulado o diafragma eletricamente (mimetizando o TMI), ocorreu também um aumento de fibras oxidativas na musculatura do diafragma ${ }^{60}$.

Está bem definido na literatura que na IC o fluxo para os músculos respiratórios está diminuído ${ }^{62}$. Supinski e cols ${ }^{103}$, através da análise de fluxo sanguíneo diafragmático, demonstraram um menor direcionamento de fluxo para fibras do diafragma na situação de fadiga muscular induzida por estimulação elétrica. Ao mesmo tempo, observou maior hiperemia reativa no diafragma de animais com IC através da oclusão / liberação da artéria frênica. O restabelecimento do volume sanguíneo ao diafragma também se encontrou prolongado, o que pode estar relacionado com a importante participação do sistema respiratório na redistribuição de débito cardíaco após o exercício ${ }^{103}$. 
A isquemia muscular diafragmática, além de alterar a função local, pode desencadear reflexos que causam aumento da atividade simpática e vasoconstrição periférica sistêmica (aumento da RVP sistêmica) mediados por ergorreceptores ${ }^{5} 102$. Portanto, o efeito benéfico do TMI pode se estender para além da musculatura respiratória, com diminuição do reflexo de vasoconstrição periférica, podendo se associar a uma melhor perfusão tecidual sistêmica.

A conseqüência funcional de tal melhora, pode ser observada no aumento da capacidade cardiorrespiratória ao exercício, aumento do consumo de oxigênio e diminuição da sensação de dispnéia aos esforços.

\section{Efeito do TMI na Capacidade Funcional Cardiorrespiratória}

Não se pode negar que o treinamento aeróbio tende a proporcionar melhoras no consumo máximo de oxigênio provocado, pelo menos em parte, por um aumento do débito cardíaco, principalmente à custa de um aumento do volume sistólico ${ }^{104}$.

$\mathrm{O}$ consumo de oxigênio de pico $\left(\mathrm{VO}_{2}\right.$ pico) medido durante o teste de esforço cardiopulmonar (TECP) é um preditor de mortalidade em pacientes com IC e um importante critério na seleção de candidatos para transplante de coração ${ }^{105}$. Braga e cols ${ }^{106}$ relataram que variáveis metabólicas e respiratórias obtidas em diferentes momentos do TECP, como limiar anaeróbio, ponto de compensação respiratório e no pico do exercício, podem predizer, de forma semelhante, o risco relativo de mortalidade em pacientes com IC.

No presente estudo, o consumo do oxigênio de pico $\left(\mathrm{VO}_{2}\right.$ pico) foi considerado o mais alto $\mathrm{VO}_{2}$ atingido no pico do exercício, o qual foi utilizado 
como índice da capacidade física máxima de cada indivíduo. Os pacientes por nós avaliados apresentaram valores iniciais médios da $\mathrm{VO}_{2}$ ao redor de $14-16$ $\mathrm{ml} / \mathrm{kg} / \mathrm{min}$ faixa considerada de risco moderado para eventos cardiovasculares 105, 107. O grupo que realizou o TMI apresentou um aumento médio do $\mathrm{VO}_{2}$ pico de 13,52 \% após doze semanas de exercício. Devemos ressaltar que o incremento da $\mathrm{VO}_{2}$ pode significar uma melhora de sobrevida desses pacientes. De fato estudo prévio demonstrou que pacientes com IC com $\mathrm{VO}_{2}$ pico < 16 ml.kg-1.min-1 tiveram pior prognóstico em relação aos pacientes com $>16$ ml.kg-1.min-1, independentemente da etiologia, da função cardíaca e do uso de beta-bloqueadores ${ }^{107}$. $\mathrm{O} \mathrm{VO}_{2}$ pico foi considerado preditor univariado e independente de sobrevida livre de evento, e a terapia com betabloqueadores não influenciou no status de predição absoluta do $\mathrm{VO}_{2}$ pico em relação à sobrevida. Este conceito está bem estabelecido para $\mathrm{VO}_{2}$ obtido durante teste com esteira ${ }^{105,108}$. Entretanto, há discussões quanto à validade do $\mathrm{VO}_{2}$ obtido em teste com cicloergômetro como marcador de sobrevida, método utilizado no nosso estudo ${ }^{109,}{ }^{110}$. Isso pode decorrer da menor massa muscular envolvida nesse tipo de ergômetro, proporcionando informações preditivas limitadas ${ }^{109}$, 110. Em pessoas saudáveis, o $\mathrm{VO}_{2}$ pico obtido em cicloergômetro foi $10 \%$ a $15 \%$ menor que aquele obtido no teste em esteira ${ }^{111,112}$. Recentemente, o valor das variáveis metabólicas e respiratórias obtidas em TECP com cicloergômetro foram demonstradas, indicando fortemente o valor deste tipo de teste na avaliação do prognóstico dos pacientes com IC ${ }^{106}$.

Em outros estudos que também utilizaram o TMI em pacientes com IC o incremento do $\mathrm{VO}_{2}$ também foi observado, variando de 16 a $20 \%{ }^{12,75,113}$. 
Entretanto, com o treinamento aeróbio de pacientes com IC pode detectar incrementos mais acentuados ${ }^{7}$.

Outras variáveis do TECP também têm demonstrado valor de prognóstico na IC, como a relação entre a ventilação (VE) e a produção de dióxido de carbono $\left(\mathrm{VCO}_{2}\right)$ expressa como inclinação $\mathrm{VE} / \mathrm{VCO}_{2}{ }^{114}$ A inclinação $\mathrm{VE} / \mathrm{VCO}_{2}$ aumentada está relacionada à diminuição da capacidade de perfusão pulmonar e ao débito cardíaco, contribuindo com o valor do prognóstico na $\mathrm{IC}^{114}$. Além disso, é geralmente independente do esforço e representa as condições reflexas dos pacientes com IC ${ }^{114}$.

Estudos têm adotado valores de limiares para definir padrões de melhor e pior prognóstico (valores $\leq 34$ e $>34$, respectivamente) do paciente com IC, para a inclinação $\mathrm{VE} / \mathrm{VCO}_{2}{ }^{114,115}$. Nossa população apresentou uma diminuição para inclinação $\mathrm{VE} / \mathrm{VCO}_{2}$ de $9,2 \%$. Novamente, podemos demonstrar que a alteração do valor médio de 35,8 para $32,5 \mathrm{ml} / \mathrm{kg} / \mathrm{min}$, muda a faixa de risco dos pacientes com IC, indicando um benefício mensurável do TMI para a nossa população.

O beta bloqueador pode interferir de forma benéfica na resposta ventilatória durante o exercício, por melhorar o perfil hemodinâmico e diminuir a atividade simpática. Porém, o valor prognóstico da inclinação $\mathrm{VE} / \mathrm{VCO}_{2}$ de pacientes tratados com betabloqueador, quando comparados com o grupo sem betabloqueador, é semelhante, ou até mais intenso ${ }^{107}$. Como na nossa população todos os pacientes estavam em uso desta droga, podemos inferir que houve um ganho real na melhora desta variável, e que a associação do TMI com o tratamento farmacológico proporciona reais benefícios aos pacientes. 
Não observamos diferenças significativas entre o grupo controle e o grupo que realizou TMI quanto à duração do exercício no cicloergômetro, assim como no momento em que ocorreram o limiar anaeróbico e o ponto de compensação respiratório, avaliados no teste ergoespirométrico.

\section{Variabilidade da FC e PA e atividade simpática nervosa periférica}

A IC é caracterizada por ativação neuro-humoral, cujos mecanismos não estão bem esclarecidos ${ }^{116}$. Entretanto, reconhece-se que 0 aumento da atividade simpática e a diminuição da variabilidade da freqüência cardíaca (VFC) são marcadores de mau prognóstico em pacientes com IC ${ }^{7}$. Estudos prévios demonstraram que o treinamento aeróbio com cicloergômetro é capaz de diminuir significativamente a atividade simpática periférica de pacientes com IC, mensurada através da técnica de microneurografia e até mesmo normalizála ${ }^{7,70}$.

$\mathrm{Na}$ população de pacientes por nós avaliada, apresentando IC de etiologia hipertensiva, em classe funcional II (NYHA), com otimização de tratamento clínico, incluindo uso de Carvedilol, observamos que o TMI levou à diminuição da atividade simpática nervosa tanto cardíaca quanto periférica.

Observamos nos pacientes com IC valores médios de ANSP na microneurografia ao redor de 35 disparos /min. Sabe-se que indivíduos normais jovens podem ter uma ampla variação na ANSP (6-34 disparos por min). No nosso laboratório indivíduos controle, avaliados em outros estudos, mas com protocolo semelhante, apresentavam valores médios de 11-25 disparos/min, 
respectivamente para faixas etárias de 20 a 40 anos, valores significativamente menores que os detectados nos portadores de IC ${ }^{117,118}$.

O decréscimo da ANSP obtido com TMI foi menor (20\%) quando comparado ao decorrente do treinamento por meio da atividade aeróbia (25\%) em pacientes com IC que também utilizavam Carvedilol ${ }^{7,70}$. Ainda, em outro grupo de pacientes com IC que não utilizava beta Bloqueador observou-se uma queda significativamente maior (63\%). Possivelmente, o impacto da redução da atividade simpática é maior na falta do beta bloqueio farmacológico prévio. Este é o primeiro trabalho clínico que demonstra o efeito do TMI na redução da ANSP em pacientes com IC hipertensiva em uso regular de beta Bloqueador.

A modulação da atividade simpática cardíaca pode ser inferida por meio da análise da variabilidade da FC nos domínios do tempo e da freqüência, com protocolos específicos para cada domínio ${ }^{119}$.

Em nosso estudo, foi observada uma significativa redução do componente LF (18\%) (atividade simpática) e significativo aumento do componente HF (17\%) (parassimpático) em valores normalizados dos pacientes que realizaram o TMI após 12 semanas. Podemos tentar discutir nossos dados com relação aos obtidos por Laoutaris e cols. ${ }^{113}$. Esse grupo não encontrou alteração na variabilidade da FC, avaliada no domínio do tempo, o que pode estar relacionado a um menor tempo de TMI (10 semanas durante três vezes na semana) e a limitações inerentes ao método usado (monitorização ECG de $24 \mathrm{~h}$ - Holter). Em recente artigo de revisão sobre impacto da atividade física aeróbia em pacientes com IC ${ }^{120}$ concluiu-se que o treinamento melhora a variabilidade da FC e a sensibilidade do baroreflexo, diminuindo ainda mediadores humorais (catecolaminas circulantes, 
angiotensina II, vasopressina e BNP). A diminuição isolada da variabilidade da FC aumenta de três a cinco vezes o risco relativo de mortalidade por evento cardíaco em pacientes pós infarto do miocárdio ${ }^{121}$; quando associado à depressão significativa da sensibilidade do barorreflexo $(<3 \mathrm{~ms} / \mathrm{mmhg})$, este risco relativo sobe para até sete vezes ${ }^{121}$. Por outro lado, indivíduos com IC congestiva que apresentam aumentos de variabilidade da FC, embora pequenos, em alguns índices, como por exemplo, o desvio padrão de intervalos $\mathrm{RR}$ normais (domínio do tempo), podem ter risco de mortalidade diminuído em até $20 \%{ }^{122}$. Por essa razão e também pela facilidade com que se pode obter esta variável em repouso (método não invasivo, sem necessidade de infusão de drogas), a atividade autonômica cardíaca obtida em repouso tem sido alvo de vários experimentos, e vem sendo considerado como um possível "alvo terapêutico", para abordagens farmacológicas e não farmacológicas ${ }^{123}$.

As adaptações da FC advindas do treinamento físico, especialmente o aeróbio, podem ser decorrentes de modificações no balanço simpato -vagal ou mesmo de adaptações intrínsecas como melhora no sistema de condução atrioventricular ${ }^{122}$. Alguns estudos sugerem que apenas a prática regular de exercícios físicos parece não ser suficiente para a diminuição efetiva do risco de mortalidade, sendo necessário que o programa de treinamento seja capaz de promover adaptações tanto na condição aeróbia ${ }^{124}$, ou na função autonômica do indivíduo ${ }^{125}$. O aumento do consumo máximo de $\mathrm{O}_{2}$ através do treinamento aeróbico pode ainda atenuar o declínio da sensibilidade do barorreflexo também relacionado ao avanço da idade ${ }^{126}$. Um programa de exercícios de intensidade leve seria suficiente para apresentar algum grau de melhora na função autonômica de indivíduos adultos saudáveis ${ }^{127}$ ou com 
insuficiência cardíaca crônica ${ }^{128}$, mesmo sem supervisão direta do treinamento 129. As alterações promovidas pelo treinamento sobre a atividade vagal seriam centrais, possivelmente atuando diretamente no barorreflexo, enquanto que a atividade simpática se relaciona primariamente com alterações periféricas (vasoconstrição) ${ }^{129}$. Essas alterações podem ser notadas já nas primeiras semanas de treinamento aeróbio em indivíduos com doença arterial coronariana e em pós-infartados . Muito embora Seals et al. ${ }^{130}$ tenham sugerido que essas melhoras devem ser mais evidenciadas em pessoas com função cardíaca anormal, acreditando que o treinamento aeróbio teria menor impacto sobre a variabilidade da FC de indivíduos saudáveis, Melanson e Freedson Stein et $a^{131,132}$, Al-Ani eT al. ${ }^{133}$ e Gallo $\mathrm{Jr}$ et al. ${ }^{134}$ obtiveram resultados expressivos com o treinamento sobre os marcadores autonômicos em indivíduos saudáveis e Levy et al. ${ }^{135}$ ainda sugerem que estes ganhos seriam independentes do fator idade. Apesar de as metodologias aplicadas terem sido bastante distintas e o tempo efetivo do treinamento ter variado de seis semanas a 12 meses, os resultados foram consonantes, demonstrando, de forma geral, um aumento da atividade vagal em decorrência do programa de exercícios ou mesmo diminuição da atividade simpática em repouso, contribuindo para as melhoras hemodinâmicas ${ }^{135}$.

Trabalhos prévios em nosso laboratório demonstraram que pacientes com HAS e IC apresentam alterações do controle reflexo cardiorrespiratório, mediadas por diferentes estímulos e envolvendo vários mecanismos reflexos, como atenuação do reflexo cardiopulmonar, hiperatividade dos quimioreceptores e diminuição da sensibilidade do baroreflexo. Em conjunto, estas alterações contribuem para $\circ$ aumento de atividade simpática dos 
pacientes com IC, tanto em repouso, quanto durante situações que estressam o sistema cardiovascular ${ }^{42,43,44}$. Dados mais recentes focando a análise da variabilidade da freqüência cardíaca, reconhecido marcador de prognóstico na IC, evidenciaram que pacientes com IC hipertensiva, mesmo em uso de Carvedilol, apresentavam aumento da atividade simpática e menor atividade parassimpática para o coração na situação de repouso, comparado com indivíduos normais ${ }^{45}$. De modo interessante, durante a modulação aguda de volume, ocorreu melhora do desequilíbrio autonômico no grupo com IC diastólica e sistólica (diminuição da atividade simpática e aumento da atividade parassimpática) ${ }^{46}$.

Podemos levantar a hipótese de que a queda da atividade simpática observada em pacientes com IC e TMI tem intensa relação com alterações no controle reflexo em resposta à modulação de volume intratorácico e em resposta a estímulos respiratório.

A existência de bases neuroanatômicas comuns na modulação do controle tanto cardiovascular como respiratório poderia ser considerada a base biológica dessa intervenção. ${ }^{136}$ Durante a execução do exercício respiratório, o volume corrente aumenta para compensar a redução da freqüência respiratória e manter a ventilação-minuto ${ }^{137}$, o que pode desencadear mudanças autonômicas por meio da redução da atividade simpática ou da ativação do reflexo de Hering-Breuer ${ }^{138}$. Para Joseph e cols., as mudanças de amplitude respiratória, isto é, de expansibilidade torácica durante o exercício respiratório, podem aumentar as flutuações dos intervalos RR, melhorando a eficiência do barorreflexo e reduzindo a pressão arterial. Esses resultados também poderiam ser explicados pela diminuição do quimiorreflexo, cujo 
aumento é bem conhecido por elevar a atividade simpática e a pressão arteria $\left.\right|^{37}$. Para Bernardi e cols. ${ }^{137}$, o treinamento respiratório melhorou a saturação de oxigênio e a regulação do quimiorreflexo, com melhora da capacidade de exercício em pacientes com doença cardiovascular. Embora não tenham sido mensuradas as trocas gasosas na amostra deste estudo, o aumento do volume corrente atribuído ao aumento da expansibilidade torácica pode ter proporcionado melhor oxigenação nesses pacientes. Outros estudos devem focar para esse parâmetro metabólico por meio de análise do volume máximo de oxigênio $\left(\mathrm{VO}_{2}\right)$ e do volume de dióxido de carbono $\left(\mathrm{VCO}_{2}\right)$.

\section{Efeito do TMI sobre o fluxo de sangue para o antebraço (FSA)}

Alem de diversas alterações morfológicas na musculatura esquelética como atrofia e distribuição entre os tipos de fibras musculares, os pacientes com IC apresentam ainda importantes alterações na relação entre capilares sanguíneos e o músculo esquelético. Essas alterações limitam a difusão de oxigênio do sangue para o tecido muscular e principalmente alterações intrínsecas do metabolismo muscular que desencadeiam acidose e fadiga precoce no exercício ${ }^{139 .}$

Zelis e cols ${ }^{140}$ sugeriram pela primeira vez que pacientes com IC apresentavam redução do fluxo sanguíneo muscular em resposta ao exercício e diversos estímulos vasodilatadores. Classicamente, pacientes com IC apresentam diversas anormalidades na circulação periférica, advindas, entre outros, da importante ativação do SNS e também da redução do fluxo 
sanguíneo muscular em repouso ${ }^{140}$. Shoemaker e cols. ${ }^{141}$ ao estudar a dinâmica do fluxo sangüíneo em pacientes com IC em resposta ao exercício de preensão manual, não observaram diferenças quando comparou pacientes com IC e indivíduos saudáveis.

Acredita-se que o fluxo sanguíneo muscular em pacientes com IC é determinado pela complexa interação de fatores vasoconstritores e vasodilatadores, que parecem funcionar de forma redundante, sendo que o funcionamento adequado deste controle é determinante para a correta interação entre o aumento no metabolismo muscular e o aporte de oxigênio para a musculatura ativa.

No presente estudo, não encontramos aumento na resposta vasodilatadora nos pacientes com IC submetidos ao TMI em repouso e durante o exercício isométrico de preensão manual. Assim como no nosso estudo, Laoutaris e cols. ${ }^{142}$ avaliaram o fluxo para antebraço em pacientes com IC e não encontraram relação entre o TMI e melhora do fluxo para o antebraço. Tal fato pode estar associado ao uso contínuo de beta bloqueador (Carvedilol)

Diferentemente, Chiappa e cols. ${ }^{143}$ demonstraram em um ensaio clínico randomizado que pacientes com IC de várias etiologias apresentaram um aumento da resposta vasodilatadora em repouso após 12 semanas de TMI.

De Matos e cols ${ }^{144}$. relataram que pacientes com IC que utilizavam Carvedilol, apresentaram uma redução da ANSP em repouso e durante exercício isométrico. Em contraponto, apesar da diminuição da ASNP, não houve um aumento de fluxo para o antebraço durante o repouso e exercício isométrico, o que vem de encontro com os achados de Kubos e cols ${ }^{145}$. Existem duas possíveis explicações para este achado: a primeira, devido a sua 
natureza não seletiva, o Carvedilol antagoniza receptores beta 2 adrenérgicos, o que limita a resposta vasodilatadora em pacientes com IC, a segunda, os receptores alfa 1 adrenérgicos atenuam o efeito vasodilatador do Carvedilol.

\section{Efeito do TMI sobre a qualidade de vida dos pacientes com IC}

A Insuficiência Cardíaca (IC) é uma síndrome complexa na qual uma desordem estrutural e/ou funcional do coração proporciona uma diminuição da capacidade do ventrículo esquerdo de se encher ou/de ejetar sangue até os níveis de pressões de enchimento fisiológico. Com isso, esses indivíduos apresentam como principal característica a limitação funcional e a dispnéia aos esforços, sendo a intolerância ao exercício o principal sintoma encontrado nesses pacientes, tendo como via final diminuição na qualidade de vida. O questionário de qualidade de vida Minessota avalia o perfil de saúde e é largamente utilizado no meio científico, apresentando boa validade para tal. Segundo a literatura atual ${ }^{146}$, por se tratar de algo complexo, que envolve conceitos multidimensionais, que relacionam aspectos físicos, psicológicos e espirituais do indivíduo, não há definição consensual de qualidade de vida (QV). Atualmente a QV pode ser definida de duas maneiras - de forma genérica ou relacionada à saúde. De maneira geral, a definição mais difundida atualmente é a da Organização Mundial da

Saúde que a define como a percepção que o indivíduo tem da sua vida, considerando seu contexto cultural, seus valores e seus sentimentos, expectativas e necessidades. Esse conceito engloba dimensões amplas, 
como o bem-estar físico, mental e social, e a relação desses aspectos com o ambiente em que vive.

De acordo com esse conceito, ter QV significa não apenas que o indivíduo tenha saúde física e mental, mas que esteja bem consigo, com a vida e com as pessoas com quem convive de modo a ser capaz de reagir de forma satisfatória frente aos problemas e ter controle sobre os acontecimentos do cotidiano ${ }^{147}$. A conceituação de $Q V$ relacionada à saúde agrega e relaciona os aspectos envolvidos na definição genérica, com a questão da doença e das intervenções em saúde ${ }^{148}$. Em geral, os portadores de problemas cardíacos sofrem modificação em seu padrão de vida normal, em virtude da incapacidade para executar determinadas tarefas cotidianas, decorrente dos sinais e sintomas da IC (dor ou desconforto precordial, dispnéia, ortopnéia, palpitação, síncope, fadiga e edema) ${ }^{148}$. Em um estudo foi descrita a dificuldade desses indivíduos em conviver com as alterações que a doença cardíaca impõe no cotidiano e com os sentimentos ameaçadores que surgem em virtude das restrições a que são submetidos 148. Observou-se, que os aspectos físicos e os aspectos emocionais representaram as dimensões mais comprometidas nos pacientes que participaram desse estudo. Esses resultados são similares aos encontrados em outros estudos, nos quais foi identificado comprometimento dos aspectos físicos em pacientes portadores de doença arterial coronariana em tratamento clínico ${ }^{149}$ e em pacientes idosos com insuficiência cardíaca ${ }^{150}$.

Sabe-se que os portadores de IC normalmente apresentam intolerância à atividade, definida pela North American Nursing Diagnosis Association ${ }^{151}$ como estado no qual um indivíduo tem energia fisiológica ou 
psicológica insuficiente para suportar ou completar as atividades diárias, requeridas ou desejadas. Em um estudo no qual foram identificados os diagnósticos de enfermagem de pacientes que se encontravam no período pré-operatório de cirurgia cardíaca, a categoria diagnóstica intolerância a atividade foi identificada em $13(88,2 \%)$ dos 17 pacientes avaliados ${ }^{151}$. Essa intolerância pode ser justificada pelo desconforto respiratório, fadiga e palpitação que esses pacientes sentem ao desenvolver suas atividades diárias, em virtude da incapacidade do coração manter um débito cardíaco suficiente para satisfazer as necessidades teciduais de oxigênio e da redução do fluxo sanguíneo periférico. Além disso, alguns estudos ${ }^{152}$ comprovaram que os portadores de insuficiência cardíaca também apresentam alterações morfológicas e metabólicas na musculatura esquelética, interferindo na capacidade desses indivíduos em realizar determinadas atividades.

Os pacientes que participaram do TMI relataram após doze semanas uma melhora na realização de atividades da vida diária, o que está relacionado com uma melhora na capacidade funcional cardiorrespiratória. $\mathrm{O}$ aumento de força dos músculos respiratórios também pode ser responsável pela melhora da sensação de dispnéia, fazendo com que os pacientes conseguissem realizar o maior número de atividades sem falta de ar. Mancinni e cols ${ }^{8}$. observaram que o TMI melhorou a qualidade de vida, avaliada pelo Questionário de Minessota após 12 semanas de treinamento, o que vem de encontro com nossos resultados. 


\section{CONCLUSÃO}

O TMI realizado durante doze semanas leva a um aumento da força e resistência da musculatura inspiratória e da capacidade cardiorrespiratória, e como conseqüência, a melhora da qualidade de vida dos pacientes com insuficiência cardíaca de etiologia hipertensiva. Além disso, o treinamento específico dos músculos respiratórios provoca uma redução da atividade simpática periférica e cardíaca, que pode trazer um benefício adicional na sobrevida dos pacientes. 


\section{BIBLIOGRAFIA}

1 Hughes PD, Polkey MI, Harrus ML, Coats AJ, Moxham J, Green M. Diaphragm strength in chronic heart failure. Am J Respir Crit Care Med. 1999 Aug;160(2):52934.

2 Daganou M, Dimopoulou I, Alivizatos PA, Tzelepis GE. Pulmonary function and respiratory muscle strength in chronic heart failure: comparison between ischaemic and idiopathic dilated cardiomyopathy. Heart. 1999 Jun;81(6):618-20.

3 Clark AL, Poole-Wilson PA, Coats AJ. Relation between ventilation and carbon dioxide production in patients with chronic heart failure. J Am Coll Cardiol. 1992 Nov 15;20(6):1326-32.

4 Mancini DM, Henson D, La Manca J, Donchez L, Levine S. Benefit of selective respiratory muscle training on exercise capacity in patients with chronic congestive heart failure. Circulation. 1995 Jan 15;91(2):320-9.

5 Piepoli M, Clark AL, Coats AJS. Muscle metaboreceptors in hemodynamic autonomic and ventilatory response to exercice in man. Am $J$ Physiol. 1985;269:1428-36. 
6 Kaufman MP, Foster HV. Reflexes controlling circulatory, ventilatory and airway responses to exercice. In: Rowel LB, Shepherd JT. Handbooks of Physiology, section 12, Exercice: Regulation and integration of multiples systems. Oxford University Press for the American Physiological Society, New York, p 381 -447.

7 Roveda F, Middlekauff HR, Rondon MU, Reis SF, Souza M, Nastari L, Barretto AC, Krieger EM, Negrão CE. The effects of exercise training on sympathetic neural activation in advanced heart failure: a randomized controlled trial. J Am Coll Cardiol. 2003 Sep 3;42(5):854-60 .

8 Leith DE, Bradley M. Ventilatory muscle strength and endurance training. J App/ Physiol. 1976 Oct;41(4):508-16.

9 Aldrich TK, Karpel JP, Uhrlass RM, Sparapani MA, Eramo D, Ferranti R. Weaning from mechanical ventilation: adjunctive use of inspiratory muscle resistive training. Crit Care Med. 1989 Feb; 17(2):143-7.

10 Reid WD, Samrai B. Respiratory muscle training for patients with chronic obstructive pulmonary disease. Phys Ther. 1995 Nov; 75(11):996-1005.

11 Gosselink R, Troosters T, Decramer M. Exercise training in COPD patients: the basic questions. Eur Respir J. 1997 Dec; 10(12): 2884-91. 
12 Dall'Ago P, Chiappa GR, Guths H, Stein R, Ribeiro JP. Inspiratory muscle training in patients with heart failure and inspiratory muscle weakness: a randomized trial. J Am Coll Cardiol. 2006 Feb 21; 47(4):757-63. Epub 2006 Jan 26.

13 Packer, M. Survival in patients with chronic heart failure and its potential modification by drug therapy. In Cohn, J.N. (ed): Drug Treatment of Heart Failure, $2^{\text {nd }}$ ed. Secaucus, N.J., ATC Internacional, 1988, p.273

14 Lyndsay, DC, Lovegrove CA, Dunn MJ, Bennet JG, Pepper JR, Yacoub MH, Poole Wilson PA. Histological abnormalities of muscle from limb, thorax and diaphragm in chronic heart failure. Eur Heart J. 1996 Aug 13; 17, 1239 -1250.

15 Mann DL. Mechanisms and models in heart failure: A combinatorial approach. Circulation. 1999 Aug 31; 100(9):999-1008.

16 McKee PA, Castelli WP, McNamara PM, Kannel WB. The natural history of congestive heart failure: the Framingham study. N Engl J Med. 1971 Dec 23;285(26):1441-6.

17 The SOLVD Investigators - Effect of enalapril on survival in patients with reduced left ventricular ejction and congestive heart failure. $N$ Engl. J. Med 1991: 325: $293-302$ 
18 Opie, LH. Heart failure and neurohumoral responses. In Opie LH. (Ed) The Heart: physiology, from cell to circulation. Philadelphia: Lippincott Willians \& Wilkins, 1998; $465-511$.

19 McAlister FA, Teo KK, Taher M, Montague TJ, Humen D, Cheung L, Kiaii M, Yim R, Armstrong PW. Insights into the contemporary epidemiology and outpatient management of congestive heart failure. Am Heart J. 1999 Jul;138(1 Pt 1):87-94

20 Revisão das II Diretrizes da Sociedade Brasileira de Cardiologia para o diagnóstico e tratamento de Insuficiência Cardíaca. Arq. Bras. Cardiol 2002; 79.

21 Rossi Neto Jm. A Dimensão do problema da Insuficiência Cardíaca do Brasil e do mundo. Revista da SOCESP 2004; 1:1 - 10.

22 Braunwald, E, Mock, M.B, Watson, J. (eds): Congestive Heart failure. Current Research and Clinical Applications. Orlando, Fla., Grune and Stratton, 1982.

23 Williams JF Jr, Sonnenblick EH, Braunwald E. Determinants of atrial contractile force in the intact heart. Am J Physiol. 1965 Dec;209(6):1061-8.

24 Mann DL. Mechanisms and models in heart failure: A combinatorial approach. Circulation. 1999 Aug 31; 100(9):999-1008. 
25 Hess B. Chronic Heart Failure: pathophysiology and therapeutic approaches 'Why is kidney so important? Eur Heart Supplements 2001; 3: G3 -G7

26 Volpe M, Savoia C, De Paolis P, Ostrowska B, Tarasi D, Rubattu S. The reninangiotensin system as a risk factor and therapeutic target for cardiovascular and renal disease. J Am Soc Nephrol. 2002 Nov;13 Suppl 3:S173-8.

27 Criteria Comitee, New York Heart Association, Inc.: Deseases of the Heart and Blood Vessels. Nomenclature and Criteria for Diagnosis, $6^{\text {th }}$ ed. Boston, Little, Brown and Co., 1964. p.114.

28 Krogh A, Lindhard J. The regulation of respiration and circulation during the initial stages of muscular work. J Physiol. 1913 Oct 17;47(1-2):112-36.

29 Coote JH, Hilton SM, Perez-Gonzalez JF. The reflex nature of the pressor response to muscular exercise. J Physiol. 1971 Jul;215(3):789-804.

30 Kao FF. An experimental study of the patways involved in exercice hyperpnea employing cross circulation techniques. In: The Regulation of human respiration, ed. Cunningham DC \& Lloyd BB, p.461 -502.

31 Kaufman MP, Foster HV. Reflexes controlling circulatory, ventilatory and airway responses to exercice. In: Rowell LB, Shepherd JT. Handbooks of Physiology, 
section 12, Exercice: Regulation and integration of multiples systems. Oxford University Press for the American Physiological Society, New York, p 381 -447.

32 Mark AL, Victor RG, Nerhed C, Wallin BG. Microneurographic studies of the mechanisms of sympathetic nerve responses to static exercise in humans. Circ Res. 1985 Sep; 57(3):461-9

33 James Y, Speck DF. Respiratory control by respiratory and diaphagmatic muscle afferents. In: Dempsey JA, Pack Al, Regulation of Brathing. Marcel Dekker New York, p. $543-82$

34 Balzamo E, Lagier-Tessonnier F, Jammes Y. Fatigue-induced changes in diaphragmatic afferents and cortical activity in the cat. Respir Physiol. 1992 Nov; 90(2):213-26.

35 Offner B, Dembowsky K, Czachurski J. Characteristics of sympathetic reflexes evoked by electrical stimulation of phrenic nerve afferents. J Auton Nerv Syst. 1992 Nov; 41(1-2):103-11.

36 Szulczyk A, Szulczyk P, Zywuszko B. Analysis of reflex activity in cardiac sympathetic nerve induced by myelinated phrenic nerve afferents. Brain Res. 1988 Apr 26; 447(1):109-15. 
37 Jammes JE. The effect of changes of extramural, intrathoracic pressure on aortic arch baroreceptors. J. Physiol. (Lond) 1971; 214:89 -103.

38 Dempsey JA, Sheel AW, St Croix CM, Morgan BJ. Respiratory influences on sympathetic vasomotor outflow in humans. Respir Physiol Neurobiol. 2002 Mar; 130(1):3-20.

39 St Croix CM, Morgan BJ, Wetter TJ, Dempsey JA. Fatiguing inspiratory muscle work causes reflex sympathetic activation in humans.J Physiol. 2000 Dec 1;529 Pt 2:493-504.

40 Scott AC, Francis DP, Davies LC, Ponikowski P, Coats AJ, Piepoli MF. Contribution of skeletal muscle 'ergoreceptors' in the human leg to respiratory control in chronic heart failure. J Physiol. 2000 Dec 15; 529 Pt 3:863-70.

41 Seals DR, Suwarno NO, Joyner MJ, Iber C, Copeland JG, Dempsey JA. Respiratory modulation of muscle sympathetic nerve activity in intact and lung denervated humans. Circ Res. 1993 Feb;72(2):440-54.

42 Otto ME, Consolim - Colombo FM, Rodrigues Sobrinho CR, Krieger EM. Pressure and Time Dependence of the Cardiovascular Reflex Response in Patients with Hypertensive Cardiomiopathy. Braz J Med Biol Res. 2004 Nov;37 (11): 1615-22. 
43 De Carvalho FC, Consolim - Colombo FM, Pastore CA, Rubira MC, Meneguetti JC, Krieger EM, Wajngarten M. Acute Reduction of Ventricular Volume Decreases QT Interval Dispersion in Elderly Subjects with and without heart failure. Am J Phisiol. 2005 May; 288: H2171-6 Epub 2004 Dec 30.

44 M. Rodrigues Sobrinho CR, Barreto Filho JÁ, Bosco Otto ME, Consolim Colombo FM, Guerra Riccio GM, Krieger ME. Abscence of forearm vasorelaxation in asymptomatic hypertensive patients with systolic dysfunction during acute systemic hypoxia. Submited ATVB,2006.

45 Santos MS, Irigoyen MC, da Silva VJ, Coelho MA, Ida F, Mady C, Krieger EM, Consolim -Colombo FM. Circulation. 2004. Oct 110(17): 47-48 Suppl.

46 Otto ME. Reflexo Cardiopulmonar na Cardiopatia Hipertensiva com ou sem disfunção ventricular esquerda. Tese (Doutorado em Ciências) - Instituto do Coração, Faculdade de Medicina, Universidade de São Paulo, 2000.

47American Thoracic Socety. Dyspnea: mechanisms, assessment, and management. A consensus statement. Am. J. Respir. Crit. Care Med. 159: 321340,1999 .

48 Mancini DM, Walter G, Reichek N, Lenkinski R, McCully KK, Mullen JL, Wilson JR. Contribution of skeletal muscle atrophy to exercise intolerance and altered muscle metabolism in heart failure. Circulation. 1992 Apr;85(4):1364-73. 
49 Joyner MJ. Congestive heart failure: More bad news from exercising muscle? Circulation 2004; 110: $2978-2979$.

50 Killian KJ, Jones NL. Respiratory muscles and dyspnea. Clin Chest Med. 1988 Jun;9(2):237-48.

51 Chua TP, Coats AJ. The lungs in chronic heart failure. Eur Heart J. 1995 Jul;16(7):882-7.

50 Collins JV, Clark TJ, Brown DJ. Airway function in healthy subjects and patients with left heart disease. Clin Sci Mol Med. 1975 Sep;49(3):217-28.

52 Lindsay DC, Lovegrove CA, Dunn MJ, Bennett JG, Pepper JR, Yacoub MH, Poole-Wilson PA. Histological abnormalities of muscle from limb, thorax and diaphragm in chronic heart failure. Eur Heart J. 1996 Aug;17(8):1239-50.

53 Black LF, Hyatt RE. Maximal respiratory pressures: normal values and relationship to age and sex. Am Rev Respir Dis. 1969 May;99(5):696-702 
54 Ravenscraft SA, Gross CR, Kubo SH, Olivari MT, Shumway SJ, Bolman RM 3rd, Hertz MI. Pulmonary function after successful heart transplantation. One year follow-up. Chest. 1993 Jan;103(1):54-8.

55 Dubach P, Myers J, Dziekan G, Goebbels U, Reinhart W, Muller P, Buser P, Stulz P, Vogt P, Ratti R. Effect of high intensity exercise training on central hemodynamic responses to exercise in men with reduced left ventricular function. $J$ Am Coll Cardiol. 1997 Jun;29(7):1591-8.

56 Eldridge FL, Millhorn DE, Kiley JP, Waldrop TG. Stimulation by central command of locomotion, respiration and circulation during exercise. Respir Physiol. 1985 Mar; 59(3): 313-37.

57 Light RW, George RB. Serial pulmonary function in patients with acute heart failure. Arch Intern Med. 1983 Mar;143(3):429-33.

58 Poole Wilson PA, Buller NP. Causes of symptons in chronic congestive heart failure and implications for treatment. Am J. Cardiol. 62: 31 A, 1988.

59 Opasich C, Ambrosino N, Felicetti G, Aquilani R, Pasini E, Bergitto D, Mazza A, Cobelli F, Tavazzi L. Heart failure-related myopathy. Clinical and pathophysiological insights. Eur Heart J. 1999 Aug; 20(16):1191-200. 
60 Mancini DM, Henson D, LaManca J, Levine S. Evidence of reduced respiratory muscle endurance in patients with heart failure. J Am Coll Cardiol. 1994 Oct; 24(4):972-81 .

61 Nishimura Y, Maeda H, Tanaka K, Nakamura H, Hashimoto Y, Yokoyama M. Respiratory muscle strength and hemodynamics in chronic heart failure. Chest. 1994 Feb; 105(2):355-9.

62 Hammond MD, Bauer KA, Sharp JT, Rocha RD. Respiratory muscle strength in congestive heart failure. Chest. 1990 Nov; 98(5):1091-4.

63 Beniaminovitz A, Lang CC, LaManca J, Mancini DM. Selective low-level leg muscle training alleviates dyspnea in patients with heart failure. J Am Coll Cardiol. 2002 Nov 6; 40(9):1602-8.

64 Mahler DA, Weinberg DH, Wells CK, Feinstein AR. The measurement of dyspnea. Contents, interobserver agreement, and physiologic correlates of two new clinical indexes. Chest. 1984 Jun; 85(6):751-8.

65 Redelmeier DA, Bayoumi AM, Goldstein RS, Guyatt GH. Interpreting small differences in functional status: the Six Minute Walk test in chronic lung disease patients. Am J Respir Crit Care Med. 1997 Apr; 155(4):1278-82. 
66 Forgiarini LA, Rubleski A., Garcia D; Tieppo J; Vercelino R; Dal Bosco A; Monteiro MB; Dias AS. Avaliação da força muscular respiratória e da função pulmonar em pacients co insuficiência cardíaca. Arq. Bras. 2007; 89 (1): 36 - 41.

67 Harms CA, Wetter TJ, McClaran SR, Pegelow DF, Nickele GA, Nelson WB, Hanson P, Dempsey JA. Effects of respiratory muscle work on cardiac output and its distribution during maximal exercise. J Appl Physiol. 1998 Aug;85(2):609-18.

68 Harms CA, Wetter TJ, St Croix CM, Pegelow DF, Dempsey JA. Effects of respiratory muscle work on exercise performance. J Appl Physiol. 2000 Jul; 89(1): 131-8.

69 Davey P, Meyer T, Coats A, Adamopoulos S, Casadei B, Conway J, Sleight P. Ventilation in chronic heart failure: effects of physical training. Br Heart J. 1992 Nov; 68(5):473-7.

70 Fraga, RF, Roveda F, de Matos LN, Braga AM, Rondon MU, Rotta DR, Brum PC, Barretto AC, Middlekauff HR, Negrão CE. Exercise training reduces sympathetic nerve activity in heart failure patients treated with carvedilol. Eur $J$ Heart Fail. 2007 Jun-Jul; 9(6-7):630-6. Epub 2007 May 
71 Ennezat PV, Malendowicz SL, Testa M, Colombo PC, Cohen-Solal A, Evans T, LeJemtel TH. Physical training in patients with chronic heart failure enhances the expression of genes encoding antioxidative enzymes. J Am Coll Cardiol. 2001 Jul;38(1):194-8.

72 Mettauer B, Zoll J, Sanchez H, Lampert E, Ribera F, Veksler V, Bigard X, Mateo P, Epailly E, Lonsdorfer J, Ventura-Clapier R. Oxidative capacity of skeletal muscle in heart failure patients versus sedentary or active control subjects. $J A m$ Coll Cardiol. 2001 Oct; 38(4): 947-54.

73 Vibarel N, Hayot M, Ledermann B, Messner Pellenc P, Ramonatxo M, Prefaut C. Effect of aerobic exercise training on inspiratory muscle performance and dyspnoea in patients with chronic heart failure. Eur J Heart Fail. 2002 Dec; $4(6): 745-51$.

74 Dubach P, Myers J, Dziekan G, Goebbels U, Reinhart W, Muller P, Buser P, Stulz P, Vogt P, Ratti R. Effect of high intensity exercise training on central hemodynamic responses to exercise in men with reduced left ventricular function. $J$ Am Coll Cardiol. 1997 Jun; 29(7):1591-8.

71 Gandevia SC. Neural mechanisms underlying the sensation of breathlessness: kinesthetic parallels between respiratory and limb muscles. Aust $N Z J$ Med. 1988 Feb; 18(1):83-91. 
72 O'Donnell DE, D'Arsigny C, Raj S, Abdollah H, Webb KA. Ventilatory assistance improves exercise endurance in stable congestive heart failure. Am J Respir Crit Care Med. 1999 Dec; 160(6):1804-11.

75 Johnson $\mathrm{PH}$, Cowley AJ, Kinnear WJ. A randomized controlled trial of inspiratory muscle training in stable chronic heart failure. Eur Heart J. 1998 Aug; 19(8):1249-53

76 Reid Wd; Warrem CP. Ventilatory muscle strenght and endurance training in elderly subjects and patients with Chronic airflow limitation: a pilot study. Phys Can; 1984; 36: $305-311$.

77 Negrão, CE; Barreto, Antônio Carlos Pereira. Cardiologia do Exercício - Do atleta ao cardiopata. Ed. Manole, 2006

78 Mancini DM, Eisen H, Kussmaul W, Mull R, Edmunds LH Jr, Wilson JR. Value of peak exercise oxygen consumption for optimal timing of cardiac transplantation in ambulatory patients with heart failure. Circulation. 1991 Mar;83(3):778-86.

79 Cohen-Solal A, Czitrom D, Geneves M, Gourgon R. Delayed attainment of peak oxygen consumption after the end of exercise in patients with chronic heart failure. Int J Cardiol. 1997 Jun 27; 60(1):23-9. 
80 Belardinelli R, Faccenda E, Volpe L, Balestra S, Perna G. Exercise training as a form of cardiovascular therapy in chronic heart failure. Ital Heart J. 2000 Oct; 1(10):653-5.

81 Gaesser GA, Poole DC. The slow component of oxygen uptake kinetics in humans. Exerc Sport Sci Rev. 1996; 24:35-71.

82 Hussain S; Chatillon A; Comtois a, Roussous C, Magder S. Chemical ativation of thin fiber phrenic afferences. II. Cardiovascular responses. J Appl Physiol. 1991; $70: 77-86$.

83 Byrd RB, Hyatt RE. Maximal respiratory pressures in chronic obstructive lung disease. Am Rev Respir Dis. 1968 Nov; 98(5):848-56.

84 Tzelepis GE, Vega DL, Cohen ME, McCool FD. Lung volume specificity of inspiratory muscle training. J Appl Physiol. 1994 Aug; 77(2): 789-94.

85 Neder JA; Neri LE. Fisiologia do Exercício Teoria e Prática. São Paulo: Artes Médicas, 2003.

86 Finometer. FMS, Finapres Medical System BV. Copyright 2003 FMS. CE0344). 
87 AAMI: American national Standard ANSI/AAMI SP10-1992: Electronic or automated sphygmomanometers. Association for the Advancement of Medical Instrumentation. 1993, Arlington, VA

88 Bos WJW, van Goudoever J, van Montfrans GA, van den Meiracker AH, Wesseling $\mathrm{KH}$ : Reconstruction of brachial artery pressure from noninvasive finger pressure measurement. Circulation 1996; 94: 1870-1875)

89 Skinner JS, McLellan TH. The transition from aerobic to anaerobic metabolism. Res Exerc Sport. 1980 Mar; 51(1):234-48.

90 Delius W, Hagbarth KE, Hongell A, Wallin BG. Manoeuvres affecting sympathetic outflow in human muscle nerves. Acta Physiol Scand. 1972 Jan; 84(1):82-94.

91 Vallbo AB, Hagbarth KE, Torebjörk HE, Wallin BG. Somatosensory, proprioceptive, and sympathetic activity in human peripheral nerves. Physiol Rev. 1979 Oct; 59(4):919-57.

92 Luz, Protásio L. Da; laurindo, Francisco Rafael Martins; Chagas, Antonio Carlos Palandri. Endotélio e doenças cardiovasculares. Atheneu, Capítulo 5. 
93 Rector TS, Cohn JN. Assesment of patient outcome with the Minessota living with heart failure questionnaire: reliability and validity during a randomized, double blind, placebo- controlled trial of pimobendam. Am Heart J 1992; 124: 1017-1025.

94 Task Force of the European Society of Cardiology and the North American Society of Pacing and electrophysiology, Heart Rate Variability: Standarts of Measurements, Physiological Interpretations, and Clinical Use. Circulation 1996; v. 93, p. $1043-1065$.

95 Meyer K. Exercise training in heart failure. Recommendations based on current research. Med. Sci Sports Exerc. 2001; 33 (4): 525 -31.

96 Guyton e Hall. Tratado de Fisiologia Médica. 9 edição

97 Hughes P, Polfrey M, Harris M, Andrew J, Moxham J, Green M. Diaphagm strength in chronic heart failure. Am J Resp Crit Care Med. 1999; 160: 529-34.

98 Evans SA, Watson L, Hawkins M, Cowley AJ, Johnston ID, Kinnear WJ. Respiratory muscle strength in chronic heart failure. Thorax. 1995 Jun;50(6):625-8.

99 Tzelepis GE, Vega DL, Cohen ME, McCool FD. Lung volume specificity of inspiratory muscle training. J Appl Physiol. 1994 Aug; 77(2):789-94. 
100 Witt JD, Guenette JA, Rupert JL, McKenzie DC, Sheel AW. Inspiratory muscle training attenuates the human respiratory muscle metaboreflex. J Physiol. 2007 Nov 1;584(Pt 3):1019-28.

101 Ribeiro JP, Chiappa GR, Neder A, Frankenstein L. Respiratory muscle function and exercise intolerance in heart failure. Curr Heart Fail Rep. 2009 Jun;6(2):95-101.

102 Harms CA, Babcock MA, McClaran SR, Pegelow DF, Nickele GA, Nelson WB, Dempsey JARespiratory muscle work compromises leg blood flow during maximal exercise. J Appl Physiol. 1997 May;82(5):1573-83.

103 Supinski G, DiMarco A, Dibner-Dunlap M. Alterations in diaphragm strength and fatiguability in congestive heart failure. J Appl Physiol. 1994 Jun;76(6):270713.

104 Poole DC, Richardson RS. Determinants of oxygen uptake. Implications for exercise testing. Sports Med. 1997 Nov;24(5):308-20.

105 Weber KT, Kinasewitz GT, Janicki JS, Fishman AP. Oxygen utilization and ventilation during exercise in patients with chronic cardiac failure. Circulation. 1982 Jun;65(6):1213-23. 
106 Braga AM,Rondon MU, Negrão CE, Wanjngarten M. Valor preditivo das variáveia ventilatórias e matabólicas para óbito em pacientes com insuficiência cardíaca. Arquivos Bras. De Cardiol.2006 Jun; 86 (6):451-58.

107 Guimarães VG, Silva MS, D’Avila VM, Ferreira SM, Silva CP, Bocchi EA. VO2 pico e inclinação VE/VCO2 na era dos betabloqueadores na insuficiância cardíaca: uma experiência brasileira.Arq. Bras Cardiol.2007.Dec;20 (10):42-8.

108 Francis DP, Shamim W, Davies LC, Piepoli MF, Ponikowski P, Anker SD, Coats AJ. Cardiopulmonary exercise testing for prognosis in chronic heart failure:continuous and independent prognostic value from VE/VCO(2)slope and peak VO(2). Eur Heart J. 2000 Jan;21(2):154-61.

109 Arena R, Myers J, Aslam SS, Varughese EB, Peberdy MA. Peak VO2 and VE/VCO2 slope in patients with heart failure: a prognostic comparison. Am Heart J. 2004 Feb;147(2):354-60.

110 Corrà U, Mezzani A, Bosimini E, Scapellato F, Temporelli PL, Eleuteri E,Giannuzzi P. Limited predictive value of cardiopulmonary exercise indices in patients with moderate chronic heart failure treated with carvedilol. Am Heart J. 2004 Mar;147(3):553-60. 
111 Lund LH, Aaronson KD, Mancini DM. Validation of peak exercise oxygen consumption and the Heart Failure Survival Score for serial risk stratification in advanced heart failure. Am J Cardiol. 2005 Mar 15;95(6):734-41.

112 Fletcher GF, Balady G, Froelicher VF, Hartley LH, Haskell WL, Pollock ML. Exercise standards. A statement for healthcare professionals from the American Heart Association. Writing Group. Circulation. 1995 Jan 15;91(2):580-615.

113 Laoutaris ID, Dritsas A, Adamopoulos S, Brown MD, Cokkinos DV.Effects of inspiratory muscle training in patients with chronic heart failure. J Am Coll Cardiol. 2008 Apr 29;51(17):1663-71.

114 Arena RA, Guazzi M, Myers J, Abella J. The prognostic value of ventilatory efficiency with beta-blocker therapy in heart failure. Med Sci Sports Exerc. 2007 Feb;39(2):213-9

115 Kleber FX, Vietzke G, Wernecke KD, Bauer U, Opitz C, Wensel R, Sperfeld A, Gläser S. Impairment of ventilatory efficiency in heart failure: prognostic impact. Circulation. 2000 Jun 20;101(24):2803-9

116 Negrao CE, Middlekauff HR. Adaptations in autonomic function during exercise training in heart failure. Heart Fail Rev. 2008 Feb;13(1):51-60. 
117 Lopes HF, Silva HB, Consolim-Colombo FM, Barreto Filho JA, Riccio GM, Giorgi DM, Krieger EM. Autonomic abnormalities demonstrable in young normotensive subjects who are children of hypertensive parents. Braz $\mathrm{J}$ Med Biol Res. 2000 Jan;33(1):51-4.

118 Andrade AC, Cesena FH, Consolim-Colombo FM, Coimbra SR, Benjó AM, Krieger EM, Luz PL. Short-term red wine consumption promotes differential effects on plasma levels of high-density lipoprotein cholesterol, sympathetic activity, and endothelial function in hypercholesterolemic, hypertensive, and healthy subjects Clinics (Sao Paulo). 2009 Oct;64(5):435-42.

119 Moraes RS, Ferlin EL, Polanczyk CA, Rohde LE, Zaslavski L, GrossJL, Ribeiro JP. Three-dimensional return map: a new tool for quantification of heart rate variability. Auton Neurosci 2000;83:90-9.

120 Gademan MG, Swenne CA, Verwey HF, van der Laarse A, Maan AC, van de Vooren H, vanPelt J, van Exel HJ, Lucas CM, Cleuren GV, Somer S, Schalij MJ, van der Wall EE. Effect of exercise training on autonomic derangement and neurohumoral activation in chronic heart failure. J Card Fail. 2007 May;13(4):294303. 
121 La Rovere MT, Pinna GD, Hohnloser SH, Marcus FI, Mortara A, Nohara R, et al. Baroreflex sensitivity and heart rate variability in the identification of patients at risk for life-threatening arrhythmias. Implications for clinical trials. Circulation 2001;103:2072-7.

122 Bilchick KC, Fetics B, Djoukeng R, Fisher SG, Fletcher RD, Singh SN, et al. Prognostic value of heart rate variability in chronic congestive heart failure (Veterans Affairs' Survival Trial of Antiarrhythmic Therapy in Congestive Heart Failure). Am J Cardiol 2002;90:24-8.

123 Routledge HC, Townend JN. Why does the heart rate response to exercise predict adverse cardiac events? Heart. 2006 May;92(5):577-8. Epub 2005 Dec 30.

124 Kavanagh T, Mertens DJ, Hamm LF, Beyene J, Kennedy J, Corey P, et al. Prediction of long-term prognosis in 12169 men referred for cardiac rehabilitation. Circulation 2002;106:666-71.

125 La Rovere MT, Bersano C, Gnemmi M, Specchia G, Schwartz PJ. Exercise induced increase in baroreflex sensitivity predicts improved prognosis after myocardial infarction. Circulation 2002; 106:945-9.

126 Hunt BE, Farquhar WB, Taylor JA. Does reduced vascular stiffening fully explain preserved cardiovagal baroreflex function in older, physically active men? Circulation 2001; 103:2424-7. 
127 Uusitalo ALT, Laitinen T, Väisänen SB, Länsimies E, Rauramaa R. Effects of endurance training on heart rate and blood pressure variability. Cli Physiol \& Func Im 2002; 22:173-9.

128 Malfatto G, Branzi G, Riva B, Sala L, Leonetti G, Facchini M. Recovery of cardiac autonomic responsiveness with low-intensity physical training in patients with chronic heart failure. Eur J Heart Fail 2002; 4:159- 66.

129 Radaelli A, Coats AJ, Leuzzi S, Piepoli M, Meyer TE, Calciati A, et al. Physical training enhances sympathetic and parasympathetic control ofheart rate and peripheral vessels in chronic heart failure. Clin Sci (Colch) 1996;91: S92-4.

130. Seals DR, Hurley BF, Hagberg JM, Schultz J, Linder BJ, Natter L, et al.Effects of training on systolic time intervals at rest and during isometric exercise in men and women 61 to 64 years old. Am J Cardiol 1985;55: 797-800.

131. Melanson EL, Freedson OS. The effect of endurance training on resting heart rate variability in sedentary adult males. Eur J Appl Physiol 2001;85:442-9. 
132 Stein PK, Ehsani AA, Domitrovich PP, Kleiger RE, Rottman JN. Effect of exercise training on heart rate variability in healthy older adults. Am Heart $\mathrm{J}$ 1999;138:567-76.

133. Al-Ani M, Munir SM, White M, Towend $\mathrm{J}$, Coote $\mathrm{JH}$. Changes in R-R variability before and after endurance training measured by power spectral analysis and by the effect of isometric muscle contraction. Eur J Appl Physiol 1996;74:397-403.

134. Gallo Jr L, Maciel BC, Marin-Neto JA, Martins LEB. Sympathetic and parasympathetic changes in heart rate control during dynamic exercise induced by endurance training in man. Brazilian J Med Biol Res 1989; 22:631-43.

135. Levy WC, Cerquera MD, Harp GD, Johannessen KA, Abrass IB, Schwartz $\mathrm{RS}$, et al. Effect of endurance exercise training on heart rate variability at rest in healthy young and older men. Am J Cardiol 1998; 82:1236-41.

136 Spyer KM. Central nervous integration of cardiovascular control. J Exp Biol. 1982; 100: 109-28.

137 Bernardi L, Spadacini G, Bellwon J, Hajric R, Roskamm H, Frey AW. Effect of breathing rate on oxygen saturation and exercise performance in chronic heart failure. Lancet. 1998; 351: 1308-11.

138 Goso $\mathrm{Y}$, Asanoi $\mathrm{H}$, Ishise $\mathrm{H}$, Kameyama $\mathrm{T}$, Hirai $\mathrm{T}$, Nozawa $\mathrm{T}$, et al. Respiratory modulation of muscle sympathetic nerve activity in patients with chronic heart failure. Circulation. 2001; 104: 418-23. 
139 Selig SE, Carey MF, Menzies DG, Patterson J, Geerling RH, Williams AD, Bamroongsuk V, Toia D, Krum H, Hare DL. Moderate-intensity resistance exercise training in patients with chronic heart failure improves strength, endurance, heart rate variability, and forearm blood flow. J Card Fail. 2004 Feb; 10(1):21-30.

140 Sinoway L, Shenberger J, Leaman G, Zelis R, Gray K, Baily R, Leuenberger U. Forearm training attenuates sympathetic responses to prolonged rhythmic forearm exercise. J Appl Physiol. 1996 Oct;81(4):1778-84.

141 Shoemaker JK, Mattar L, Kerbeci P, Trotter S, Arbeille P, Hughson RL. WISE 2005: stroke volume changes contribute to the pressor response during ischemic handgrip exercise in women. J Appl Physiol. 2007 Jul;103(1):228-33. Epub 2007 Apr 5.

142 Laoutaris ID, Dritsas A, Brown MD, Manginas A, Kallistratos MS, Chaidaroglou A Degiannis D, Alivizatos PA, Cokkinos DV. Effects of inspiratory muscle training on autonomic activity, endothelial vasodilator function, and $\mathrm{N}$-terminal pro-brain natriuretic peptide levels in chronic heart failure. J Cardiopulm Rehabil Prev. 2008 Mar Apr;28(2):99-106. 
143 Chiappa GR, Roseguini BT, Vieira PJ, Alves CN, Tavares A, Winkelmann ER, Ferlin EL, Stein R, Ribeiro JP. Inspiratory muscle training improves blood flow to resting and exercising limbs in patients with chronic heart failure. J Am Coll Cardiol. 2008 Apr 29;51(17):1663-71.

144 De Matos LD, Gardenghi G, Rondon MU, Soufen HN, Tirone AP, Barretto AC, Brum PC, Middlekauff HR, Negrão CE. Impact of 6 months of therapy with carvedilol on muscle sympathetic nerve activity in heart failure patients. J Card Fail. 2004 Dec;10(6):496-502.

145 Kubo T, Azevedo ER, Newton GE, Parker JD, Floras JS. Lack of evidence for peripheral alpha(1)- adrenoceptor blockade during long-term treatment of heart failure with carvedilol. J Am Coll Cardiol. 2001 Nov 1;38(5):1463-9.

146 Seidl EMF, Zannon CMLC. Qualidade de vida e saúde: aspectos conceituais e metodológicos. Cad Saúde Pública = Rep Public Health. 2004; 20(2): 580-8.

147 The World Health Organization Quality of Life assessment (WHOQOL): position paper from the World Health Organization. Soc Sci Med. 1995; 41(10): 1403-9. 
148 Measuring Healthy Days. Population Assessment of Health-Related Quality of Life. Centers for Disease Control and Prevention. National Center for Chronic Disease Prevention and Health Promotion. Division of Adult and Community Health [ Internet]. Atlanta-Georgia: CDC; 2000 Nov [cited 2007 May 16]. Available: form: http://www.cdc.gov/hrgol/pdfs/mhd.pdf

149 Qualidades de vida em portadores de doença arterial coronária: comparação entre gêneros. Rev Assoc Med Bras. (1992). 2006; 52(4): 236-41.

150 Witham MD, Crighton LJ, McMurdo ME. Using an individualised quality of life measure in older heart failure patients. Int J Cardiol. 2007; 116(1): 40-5. 24. North American Nursing Diagnosis

151 North American Nursing Diagnosis Association. Diagnósticos de enfermagem da NANDA: definições e classificações 2007-2008. Porto Alegre: Artmed; 2007.

152 Drexler H, Riede U, Münzel T, König H, Funke E, Just H.Alterations of skeletal muscle in chronic heart failure. Circulation. 1992; 85(5): 1751-9. 